ARTICLE

\title{
Adaptive thermogenesis enhances the life-threatening response to heat in mice with an Ryr1 mutation
}

Hui J. Wang (1) 1,2,8, Chang Seok Lee ${ }^{1,8}$, Rachel Sue Zhen Yee ${ }^{1}$, Linda Groom³, Inbar Friedman ${ }^{4}$, Lyle Babcock1, Dimitra K. Georgiou (1) ${ }^{1}$, Jin Hong ${ }^{1}$, Amy D. Hanna ${ }^{1}$, Joseph Recio ${ }^{1}$, Jong Min Choi ${ }^{5}$, Ting Chang ${ }^{1}$, Nadia H. Agha , Jonathan Romero ${ }^{1}$, Poonam Sarkar ${ }^{6}$, Nicol Voermans ${ }^{7}$, M. Waleed Gaber ${ }^{1,6}$, Sung Yun Jung (iD ${ }^{5}$, Matthew L. Baker ${ }^{5}$, Robia G. Pautler ${ }^{1}$, Robert T. Dirksen ${ }^{3}$, Sheila Riazi ${ }^{4}$ \& Susan L. Hamilton (1) ${ }^{1 凶}$

Mutations in the skeletal muscle $\mathrm{Ca}^{2+}$ release channel, the type 1 ryanodine receptor (RYR1), cause malignant hyperthermia susceptibility (MHS) and a life-threatening sensitivity to heat, which is most severe in children. Mice with an MHS-associated mutation in Ryr1 (Y524S, YS) display lethal muscle contractures in response to heat. Here we show that the heat response in the YS mice is exacerbated by brown fat adaptive thermogenesis. In addition, the YS mice have more brown adipose tissue thermogenic capacity than their littermate controls. Blood lactate levels are elevated in both heat-sensitive MHS patients with RYR1 mutations and YS mice due to $\mathrm{Ca}^{2+}$ driven increases in muscle metabolism. Lactate increases brown adipogenesis in both mouse and human brown preadipocytes. This study suggests that simple lifestyle modifications such as avoiding extreme temperatures and maintaining thermoneutrality could decrease the risk of life-threatening responses to heat and exercise in individuals with RYR1 pathogenic variants.

\footnotetext{
${ }^{1}$ Department of Molecular Physiology and Biophysics, Baylor College of Medicine, Houston, TX, USA. ${ }^{2}$ Translational Biology and Molecular Medicine Graduate Program, Baylor College of Medicine, Houston, TX, USA. ${ }^{3}$ Department of Pharmacology and Physiology, University of Rochester Medical Center, Rochester, NY, USA. ${ }^{4}$ Department of Anesthesiology, University of Toronto, Toronto, ON, Canada. ${ }^{5}$ Advance Technology Core, Mass Spectrometry Proteomics Core, Baylor College of Medicine, Houston, TX, USA. ${ }^{6}$ Department of Pediatrics, Baylor College of Medicine, Houston, TX, USA. ${ }^{7}$ Department of Neurology, Donders Institute for Brain, Cognition and Behavior, Radboud University Medical Centre, Nijmegen, Netherlands. ${ }^{8}$ These authors contributed

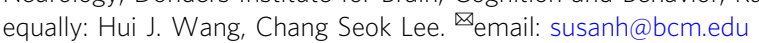


$\mathrm{M}$ alignant hyperthermia (MH) is a life-threatening response to volatile anesthetics, characterized by muscle rigidity, hyperthermia, rhabdomyolysis, acidosis, tachycardia, and, if untreated, death ${ }^{1}$. The prevalence of $\mathrm{MH}$ susceptibility (MHS) has been estimated to be as high as 1 in $2000^{2-4}$. In adults, $\mathrm{MH}$ episodes are more frequently reported in males than females ${ }^{5,6}$. Children are more likely than adults to experience an $\mathrm{MH}$ episode in response to anesthesia ${ }^{7}$. Most mutations that underlie human MHS are in the skeletal muscle $\mathrm{Ca}^{2+}$ release channel (RYR1) ${ }^{8,9}$. Triggers such as volatile anesthetics and/or heat cause the uncontrolled release of $\mathrm{Ca}^{2+}$ from the sarcoplasmic reticulum (SR) via RYR1, leading to sustained muscle contractures. Without proper intervention, the mortality rate following an $\mathrm{MH}$ episode in patients is extremely high ${ }^{8}$. Administration of dantrolene, currently the only FDA approved intervention for $\mathrm{MH}^{8}$, has effectively reduced the deaths from anesthesia in $\mathrm{MH}$ susceptible patients 8 .

Some individuals with MHS variants in RYR1 suffer from myalgia, rhabdomyolysis and muscle cramps, and can experience a life-threatening $\mathrm{MH}$-like response to heat and/or exercise ${ }^{10-21}$. Exercise, fever 22 and elevated environmental temperatures with high humidity increase the risk of these MH-like episodes ${ }^{11}$. The heat-induced episodes, however, often occur in nonclinical settings where immediate administration of dantrolene is impractical $^{23}$. Both anesthetic MH episodes and non-anesthetic MH-like responses to heat are highly variable with respect to probability of occurrence and disease presentation both for a single patient and among family members with the same mutation ${ }^{6,19}$. This variability in presentation makes prevention of life-threatening responses to heat or anesthetics challenging.

We previously created mice with a mutation in Ryrl (Y524S, YS) homologous to an MHS causative variant in humans (Y522S) 24,25 . The YS mutation in RYR1 decreases the stability of the closed state of the channel, leading to a temperature-dependent $\mathrm{Ca}^{2+}$ leak from the SR into the cytosol ${ }^{24,25}$. Increased cytosolic $\mathrm{Ca}^{2+}$, in turn, increases the sensitivity of RYR1 to opening in response to membrane depolarization or RYR1 activators (e.g., halothane, caffeine) leading to massive $\mathrm{Ca}^{2+}$ release and sustained whole body muscle contractures ${ }^{25}$. Volatile anesthetics, elevated environmental temperatures, and exercise trigger lethal MH and MH-like episodes in YS mice ${ }^{26}$. Similar to human MHS, the $\mathrm{MH}$ and $\mathrm{MH}$-like responses of the YS mice are characterized by sustained whole-body muscle contractures which lead to hyperthermia, hyperventilation, rhabdomyolysis and, ultimately, death ${ }^{24}$.

Skeletal muscle ${ }^{27-30}$ and brown adipose tissue (BAT) ${ }^{31-33}$ are the two principal sites for adaptive thermogenesis. BAT is a specialized thermogenic tissue that expresses high levels of the mitochondrial uncoupling protein (UCP1) $)^{31}$. In infants and young children, BAT has an established role in maintaining body temperature ${ }^{34}$. Functional imaging has demonstrated that adults also have significant amounts of metabolically active brown fat and the amount of BAT positively correlates with metabolic fitness ${ }^{35-37}$. While adaptive thermogenesis in brown fat is a critical component of temperature and energy regulation in both humans and mice, pathological roles of brown fat are not well-known.

In this study, we investigate the role of adaptive thermogenesis in the response of the YS mice to heat. We demonstrate that conditions that activate BAT thermogenesis increase the probability of an MH-like response during a subsequent heat exposure. Conversely, decreasing BAT activation by small increases in housing temperature of the mice decreases the probability of death of the YS mice upon subsequent exposure to heat. These findings suggest that simple lifestyle modifications could decrease the probability of a life-threatening heat response in humans, especially in children, with RYR1 mutations. Surprisingly, we found that the thermogenic capacity of YS mice is higher than that of their wild-type (WT) littermates. We demonstrate that this increase in BAT thermogenic capacity is at least partially due to the ability of muscle-derived circulating lactate, elevated in the YS mice, to promote brown/beige adipogenesis by upregulating UCP1 expression.

\section{Results}

Pediatric and male predominance of heat sensitivity in humans and mice with MHS-associated mutations. Human RYR1 mutations that underlie MHS are also frequently associated with heat and/or exercise-induced rhabdomyolysis, exercise intolerance, heat-induced muscle cramps, and death ${ }^{19,38-40}$. We conducted a retrospective cohort study and systematic review on RYR1 variants, age, gender, clinical symptoms and survival outcomes observed in heat-sensitive individuals with RYR1 variants associated with MHS. We evaluated the heat sensitivity in human carriers of RYR1 variants that were referred to the MH Investigation Unit (MHIU) at Toronto General Hospital between 1994 and 2019 (Supplementary Data 1). We also analyzed published case reports and case series of heat and exercise sensitivity associated with RYR1 mutations (Supplementary Data 2). We found the mortality rate after heat-induced episodes in individuals with RYR1 variants associated with MHS in the pediatric subgroup was significantly higher compared to that of adults (Fig. 1a). Children ( $<11$ year of age) are the most vulnerable, with a mortality rate of up to $50 \%$ following heat-induced episodes. While many children experienced life-threatening responses to heat, adults with similar $R Y R 1$ mutations generally experienced only muscle cramps or exercise intolerance (Supplementary Datas 1 and 2). Similar to previously reported findings for anesthetic-induced $\mathrm{MH}$ cases $^{41,42}$, the proportion of heatsensitive patients observed in male carriers of RYR1 variants was significantly higher compared to that of the female carriers (Fig. 1b, c). Analysis for the pathogenicity of the heat-sensitivity associated variants in RYR1 using the HumDiv-trained PolyPhen model ${ }^{43}$ confirmed that most of the variants are predicted to be deleterious (Fig. 1d). In particular, highly pathogenic RYR1 variants associated with heat-sensitivity were frequently found at subunit interfaces near the solenoid structure at the $\mathrm{N}$-terminal domain (Nsol), within the junctional solenoid (JSol), and the bridging solenoid (Bsol) in the cytosolic shell, and at the channel pore domain (Pore) at the C-terminus, based on the previously defined RYR1 domain organization ${ }^{44}$. The heat-sensitivity associated variants mapped to similar domains as the variants associated with pharmacologically induced $\mathrm{MH}$ episodes throughout the RYR1 structure with multiple overlapping residues (Supplementary Fig. 1).

We previously reported the heat sensitivity of the mouse model of MH with a Ryri $1524 S$ (YS) mutation homologous to a MHS causative mutation $24,28,29$. The YS mice exhibit severe hypermetabolism (elevated $\max \mathrm{VO}_{2}$ and $\operatorname{maxVCO}{ }_{2}$ ) and hyperthermia (core body temperature $\geq 40^{\circ} \mathrm{C}$ ) during a 15 -min exposure to $37^{\circ}$ C (Supplementary Fig. 2), leading to significantly reduced survival within $48 \mathrm{~h}$ of the heat exposure ${ }^{28,29}$. Consistent with the male and pediatric predominance in humans, we found that the survival rate for male YS mice was significantly lower than that of female YS mice following the same heat exposure (Fig. 1e). In addition, the heat-induced hypermetabolic response was more severe in young compared to old YS mice (Fig. 1f). While most YS mice less than 8 weeks of age did not survive the heat exposure, we found YS mice over 20 weeks of age were protected from heatinduced death (Fig. 1g, h). Given these findings, we focused our study on defining the underlying mechanisms for the enhanced life-threatening susceptibility to heat within the most vulnerable 

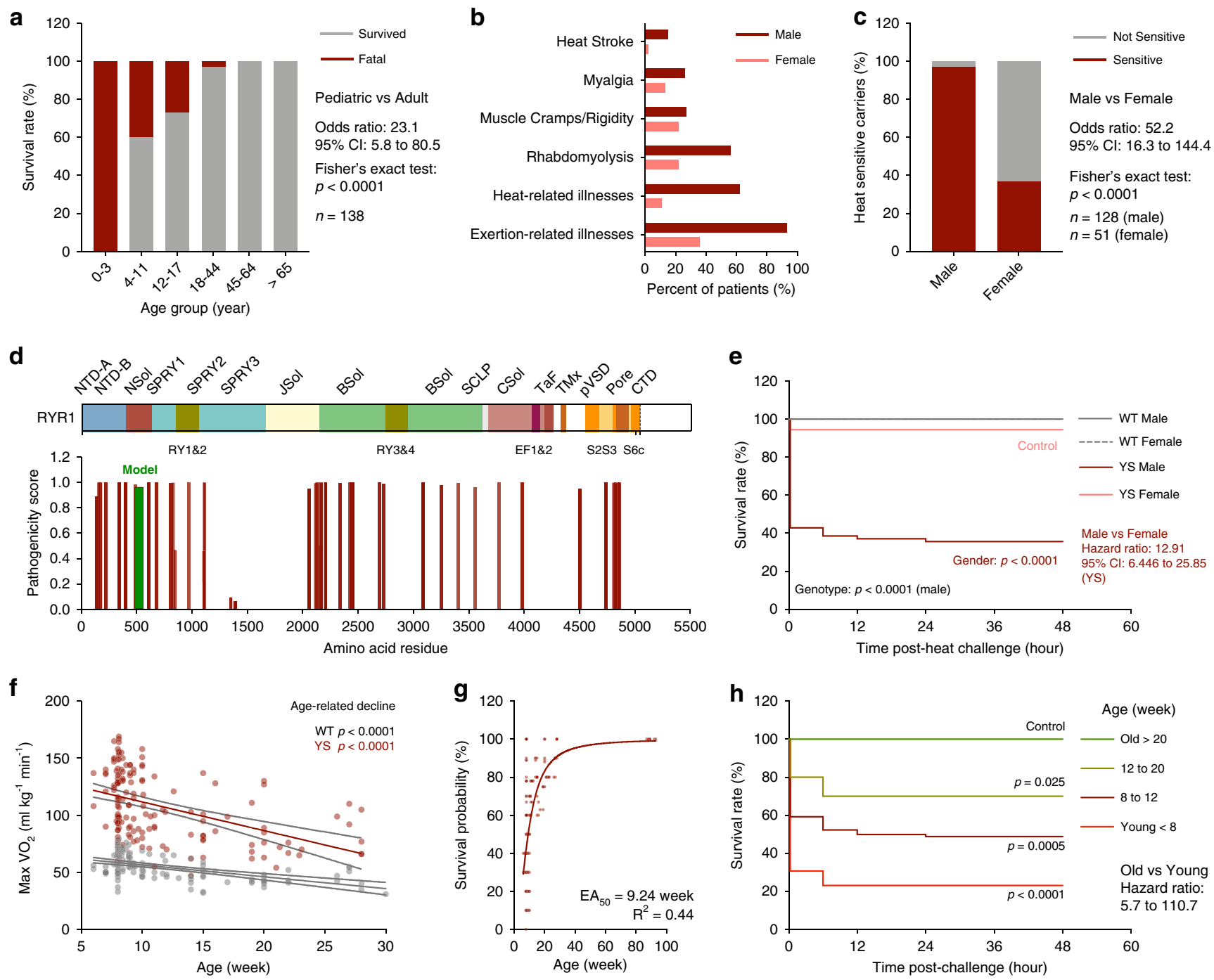

Fig. 1 Heat intolerance in patients and mice with RYR1 pathogenic variants associated with malignant hyperthermia susceptibility (MHS). a Survival rate of heat intolerant patients carrying RYR1 variants associated with MHS among age groups. b Symptoms associated with heat intolerance in male and female carriers. c Proportion of symptomatic carriers with heat-intolerant symptoms in male and female carriers. d Pathogenicity of $R Y R 1$ variants associated with heat-sensitivity. e Kaplan-Meier analysis of the survival rate of WT ( $n=50$, male and $n=12$, female) and YS ( $n=70$, male and $n=18$, female) mice after acute heat challenge. $\mathbf{f}$ Relationship of the age of mice and maxVO $\mathrm{O}_{2}$ during acute heat challenge in WT $(n=125)$ and YS $(n=151)$ mice. $\mathbf{g}$ Effect of age on the estimated survival probability of YS mice $(n=159)$ after acute heat challenge. $\mathbf{h}$ Kaplan-Meier analysis of the heat challenge survival rate of YS mice $(n=124)$ grouped by age. All mice were housed at room ambient temperature $\left(20.2 \pm 0.4^{\circ} \mathrm{C}\right)$ prior to heat challenge. All mice were within the controlled age range $(8.9 \pm 0.9$ week old $)$ at the time of the study, except for the age-dependent experiments $(\mathbf{f}-\mathbf{h})$. $P$ values are indicated as analyzed by Fisher's exact test $(\mathbf{a}, \mathbf{c})$, Mantel-Cox log-rank test $(\mathbf{e}, \mathbf{h})$, and F-test for deviation from zero-slope of linear regression (f). All statistical tests are twosided. $R^{2}$ values are indicated to quantify goodness-of-fit to non-linear regression with variable slope (g). Data are represented as mean $\pm 95 \%$ confidence intervals $(\mathrm{Cl})$ from the linear best-fit line (f). Survival probability of each muse is estimated based on the survival rate from ten mice in the respective age subgroups ( $\mathbf{g}$. Effect of age of the YS mice on survival of the heat challenge was determined by assessing survival probability as a function of age. The $E A_{50}$ is defined as the half-maximal effective age $(\mathbf{g})$. The effect of age on survival of individuals (panel $\mathbf{a}$ ) with RYR1 mutations was also assessed. The pediatric subgroup is defined as 17 years of age and younger, and the adult subgroup is defined as 18 years of age and older. Sample sizes, odds ratios, and $95 \%$ confidence intervals $(\mathrm{Cl})$ are indicated. Source data are provided as a source data file.

pediatric male populations. Thus, all experiments discussed here used young $(<12$ weeks of age $)$ male mice unless otherwise specified. The molecular mechanisms underlying the gender differences in heat sensitivity are currently being explored in a separate study.

MHS has also been associated with a muscular phenotype in human males ${ }^{41}$. While we did not detect significance differences in body weight, lean mass, metabolic rate, energy preference, and activity between YS and WT mice at basal condition, we found a small but significant decrease in overall fat mass in the YS mice, despite increased food consumption (Supplementary Fig. 3).
Adaptive thermogenesis increases the heat sensitivity of the YS mice by elevating core body temperature. We have previously demonstrated that the Y524S mutation in RYR1 causes temperature-dependent increases in $\mathrm{SR} \mathrm{Ca}^{2+}$ leak and muscle basal tension $^{24,25}$. To test the temperature-dependence of the hypermetabolic response in these mice, we exposed YS and WT mice for $15 \mathrm{~min}$ to four different temperature conditions and measured maximal $\mathrm{VO}_{2}$ using indirect calorimetry (Fig. 2a). The hypermetabolic response is detected at temperatures as low as $32^{\circ} \mathrm{C}$.

Consistent with the previously unexplained observations with multiple mouse model of $\mathrm{MHS}^{45-47}$, we detected a small, but 

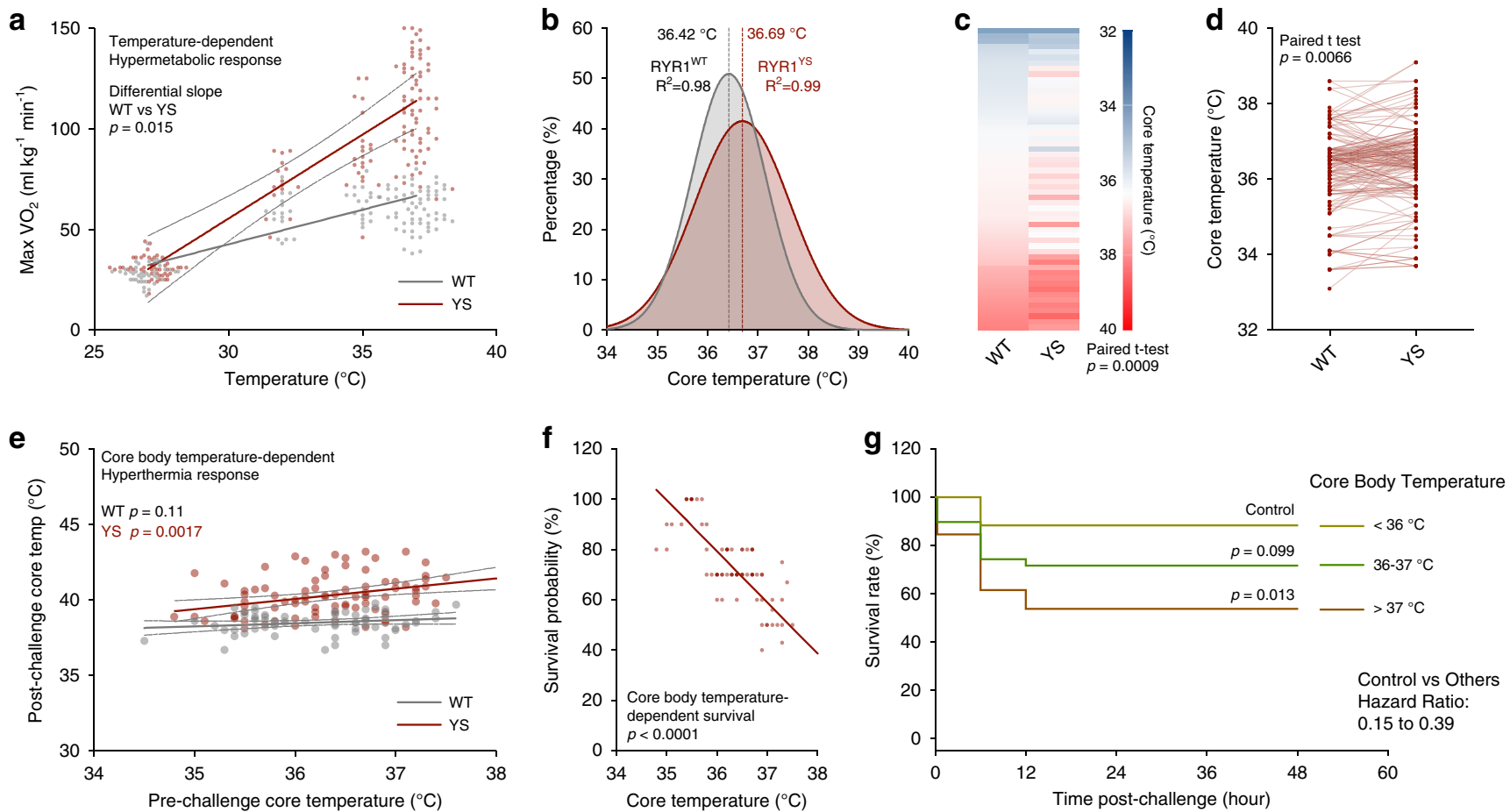

Fig. 2 Enhanced heat sensitivity and elevated core body temperature in Y524S mice. a Maximum oxygen consumption rate $\left(\mathrm{maxVO}_{2}\right)$ of $\mathrm{WT}(n=92)$ and YS $(n=115)$ mice during heat challenge at the indicated temperatures. $\mathbf{b}$ Distribution of baseline core body temperature of WT $(n=175)$ and YS ( $n=$ 202) mice at room temperature. $\mathbf{c}$, $\mathbf{d}$ Comparison of baseline core body temperatures of WT and YS mice in littermate pairs analyzed per litter (c $n=56$ pairs) and per individual animals ( $\mathbf{d} n=177$ pairs). e Relationship of baseline core body temperature and hyperthermia response after acute $37^{\circ} \mathrm{C}$ heat challenge in WT $(n=66)$ and YS $(n=85)$ mice. $\mathbf{f}$ Effect of baseline core body temperature on the estimated survival probability of YS mice $(n=85)$ after acute heat challenge. $\mathbf{g}$ Kaplan-Meier analysis of the heat challenge survival rate of YS mice $(n=85)$ grouped by baseline core body temperature. All mice were housed at room ambient temperature $\left(20.2 \pm 0.4^{\circ} \mathrm{C}\right)$ prior to heat challenge. All mice were within the controlled age range $(8.9 \pm 0.9$ week old $)$ at the time of study. $P$ values are indicated as analyzed by $F$-test for differential slope of linear regressions (a), paired $t$ test (c, $\mathbf{d}), F$-test for deviation from zero-slope of linear regression $(\mathbf{e}, \mathbf{f})$, and Mantel-Cox log-rank test $(\mathbf{g})$. All statistical tests are two-sided. $R^{2}$ values are indicated to quantify goodness-offit to Gaussian distribution (b). Survival probability of each mouse is estimated based on the survival rate from ten mice in the respective core body temperature (f) subgroups. Data are represented as asymmetrical $95 \%$ confidence intervals $(\mathrm{Cl})$ from linear best-fit line (a, e). Source data are provided as a source data file.

significant elevation of baseline core body temperature in the YS mice compared to their WT littermates even in the absence of exposure to heat (Fig. 2b-d). While the core body temperatures of all YS and WT mice were within the physiological range (Fig. 2b), the YS mice had significant elevations in core body temperatures compared to their WT littermates at room temperature prior to heat exposure as assessed with paired $t$ tests and analyzed per litter (Fig. 2c) and per individual animal (Fig. 2d). To assess the impact of this small difference in baseline core body temperature on the response to heat, we compared the core body temperature before and after heat exposure (Fig. 2e) and body temperature before heat exposure with survival of the heat challenge (Fig. 2f, g). We found that baseline core body temperature predicts both post-heat exposure body temperature and the survival of the YS mice. These results suggest that small elevations in body temperature prior to heat exposure can sensitize the YS mice to a more severe response to heat and/or heat-induced death. Thus, factors that affect core body temperature such as age, exercise, hormones, stress, and environment, could increase the risk of a life-threatening response to heat in both mice and humans.

The correlation of core body temperature prior to heat exposure with survival of the YS mice after heating suggests a possible role for adaptive thermogenesis in sensitizing the YS mice to heat. Adaptive thermogenesis is a bioenergetic process that elevates metabolic rate and generates heat in response to changes in environmental temperature or food intake and is a critical factor for maintenance of the core body temperature in endothermic mammals ${ }^{48}$. Housing temperatures in most animal vivaria are $20-22^{\circ} \mathrm{C}$, which is significantly below thermoneutrality for mice $\left(30-32^{\circ} \mathrm{C}\right)^{49}$. Hence, adaptive thermogenesis at these housing temperatures is required to maintain body temperature in both WT and YS mice. To evaluate the effect of housing temperature on heat response of YS mice, we performed a retrospective study on the relationship between housing temperatures and the response of the YS mice to heat. We found that survival of the heat-exposed YS mice correlated with small fluctuations between 19 and $21^{\circ} \mathrm{C}$ in the indoor ambient temperature of the animal housing facility arising from the seasonal changes in air conditioning (Supplementary Fig. 4). The YS mice housed at lower ambient temperatures exhibited more severe responses to the heat exposure (Fig. 3a, b). Notably, while most YS mice did not survive the heat exposure, YS mice housed for longer periods at warmer ambient temperatures, for the most part, were protected from the heat-induced death (Fig. 3c).

To further test the role of adaptive thermogenesis in the sensitivity of the YS mice to heat, we preconditioned mice at controlled cold ambient $\left(4^{\circ} \mathrm{C}\right)$, standard animal facility room temperature $\left(20.2 \pm 0.4^{\circ} \mathrm{C}\right)$ or controlled warm ambient $\left(30^{\circ} \mathrm{C}\right)$ for 1 week prior to the heat exposure. Using indirect calorimetry, we detected a marked increase of heat production induced by cold ambient temperatures in both WT and YS mice (Supplementary Fig. $5 \mathrm{a}-\mathrm{c})$. This increase in heat production was not associated 

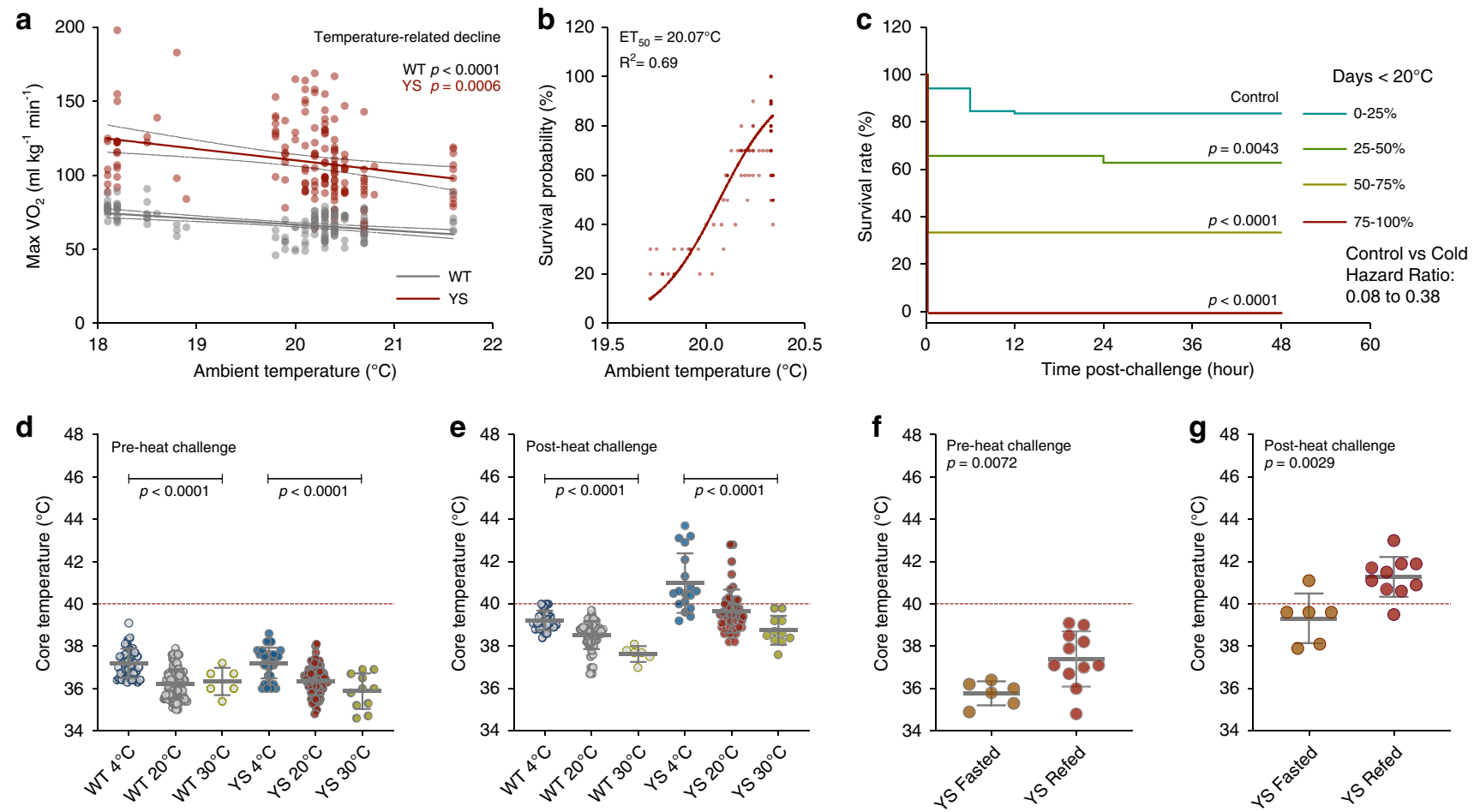

Fig. 3 Enhanced heat sensitivity and adaptive thermogenesis in Y524S mice. a Relationship of ambient housing temperature and the maxVO ${ }_{2}$ during acute $37^{\circ} \mathrm{C}$ heat challenge in WT $(n=129)$ and YS $(n=154)$ mice. $\mathbf{b}$ Effect of prior median ambient housing temperature on estimated survival probability of YS mice $(n=154)$ after acute heat challenge. $\mathbf{c}$ Kaplan-Meier analysis of the heat challenge survival rate of YS mice $(n=154)$ grouped by duration of prior ambient housing temperature at lower than $20^{\circ} \mathrm{C}$. d, e Core body temperature before (d) and after (e) acute $37^{\circ} \mathrm{C}$ heat challenge in WT and YS mice preconditioned for 1 week at $4{ }^{\circ} \mathrm{C}\left(\mathrm{WT} n=23, \mathrm{YS} n=21\right.$ ), room temperature (WT $n=35, \mathrm{YS} n=40$ ), and $30^{\circ} \mathrm{C}(\mathrm{WT} n=6, \mathrm{YS} n=11)$ ambient environment. $\mathbf{f}, \mathbf{g}$ Core body temperature before $(\mathbf{f})$ and after $(\mathbf{g})$ acute $37^{\circ} \mathrm{C}$ heat challenge in YS mice preconditioned at fasted $(n=6)$ and refed state ( $n=11$, post-heat challenge temperature of one refed YS mice was not measured due to full body contracture). All mice were within the controlled age range $(8.9 \pm 0.9$ week old) at the time of study. $P$ values are indicated as analyzed by F-test for deviation from zero-slope of linear regression (a),

Mantel-Cox log-rank test (c), ordinary one-way analysis of variance (ANOVA) with Dunnett's multiple comparisons test (d, e) and Welch's $t$ test (f, $\mathbf{g}$ ). All statistical tests are two-sided. $R^{2}$ values are indicated to quantify goodness-of-fit to nonlinear regression with variable slope (b). Survival probability of each mouse is estimated based on the survival rate from ten mice in the respective ambient temperature (b) subgroups. Effect of ambient housing temperature on heat challenge survival is measured by half-maximal effective ambient housing temperature $\left(\mathrm{ET}_{50}\right)$ on the estimated survival probability (b). Data are represented as asymmetrical $95 \%$ confidence intervals $(\mathrm{Cl})$ from linear best-fit line $(\mathbf{a})$, or mean \pm standard deviation (d-g). Source data are provided as a source data file.

with changes in cage activity in the YS mice (Supplementary Fig. 5d-f). During the preconditioning in cold, adaptive thermogenesis was adequate to compensate for the decrease in environmental temperature, resulting in no significant change in core body temperature. However, when mice were removed from cold and subjected to warmer room temperature, the adaptive thermogenesis overcompensated to significantly increase core body temperature in both WT and YS mice (Supplementary Fig. 5g-i). The cold-induced adaptive thermogenesis sensitizes the YS mice to heat, leading to severe hyperthermia $\left(\geq 40^{\circ} \mathrm{C}\right)$ after heat exposure (Fig. 3d, e). In contrast, inhibition of adaptive thermogenesis by preconditioned mice at warm ambient temperature close to thermoneutrality decreased the hyperthermic response in YS mice (Fig. 3d, e).

Food intake also activates adaptive thermogenesis ${ }^{50}$. Food intake following overnight food deprivation (refed) increased both core body temperature (Fig. 3f) and the hypermetabolic response (Fig. 3g) compared to fasted YS mice. Collectively, these results suggest that, while cold and diet-activated thermogenesis is crucial for maintaining core body temperature in WT mice, adaptive thermogenesis can be detrimental to the heat-sensitive YS mice.

BAT, which highly expresses the mitochondrial uncoupling protein (UCP1), is specialized for adaptive thermogenesis. We examined the effects of temperature preconditioning on the morphology of interscapular BAT (iBAT). Consistent with previous reports ${ }^{27,51}$, the iBAT in mice housed at $4{ }^{\circ} \mathrm{C}$ displayed multilocular lipid droplets and more compact adipocyte structure (Supplementary Fig. 5j). In contrast, the iBAT in mice exposed to $30^{\circ} \mathrm{C}$ had enlarged and unilocular lipid droplets in brown adipocytes, resembling the metabolically dormant white adipocytes (Supplementary Fig. 5j). Consistent with the morphological changes, UCP1 levels were highest in the BAT of both YS and WT mice preconditioned at $4{ }^{\circ} \mathrm{C}$ and lowest in these mice preconditioned at $30^{\circ} \mathrm{C}$ (Supplementary Fig. 5k, l).

Genetic and pharmacological modulation of BAT activity alters heat-sensitivity of YS mice. To test the role of UCP1mediated thermogenesis in the heat response of YS mice, we genetically ablated UCP1 in the YS mice by crossing UCP1deficient mice $\left(U c p 1^{-/-}\right)$with YS mice to generate YS/Ucp1 $1^{+/-}$ mice. We confirmed that UCP1 levels in heterozygous mice were effectively reduced to approximately $65 \%$ and $55 \%$ of the UCP1intact WT and YS mice at the protein level in brown fat, respectively (Supplementary Fig. 6a, b). The UCP1 deficiency was associated with reduced maximal $\mathrm{VO}_{2}$ (Fig. 4a) and $\mathrm{VCO}_{2}$ (Fig. 4b) upon heat challenge of the YS mice and improved their survival of the heat exposure (Fig. 4c) compared to the 

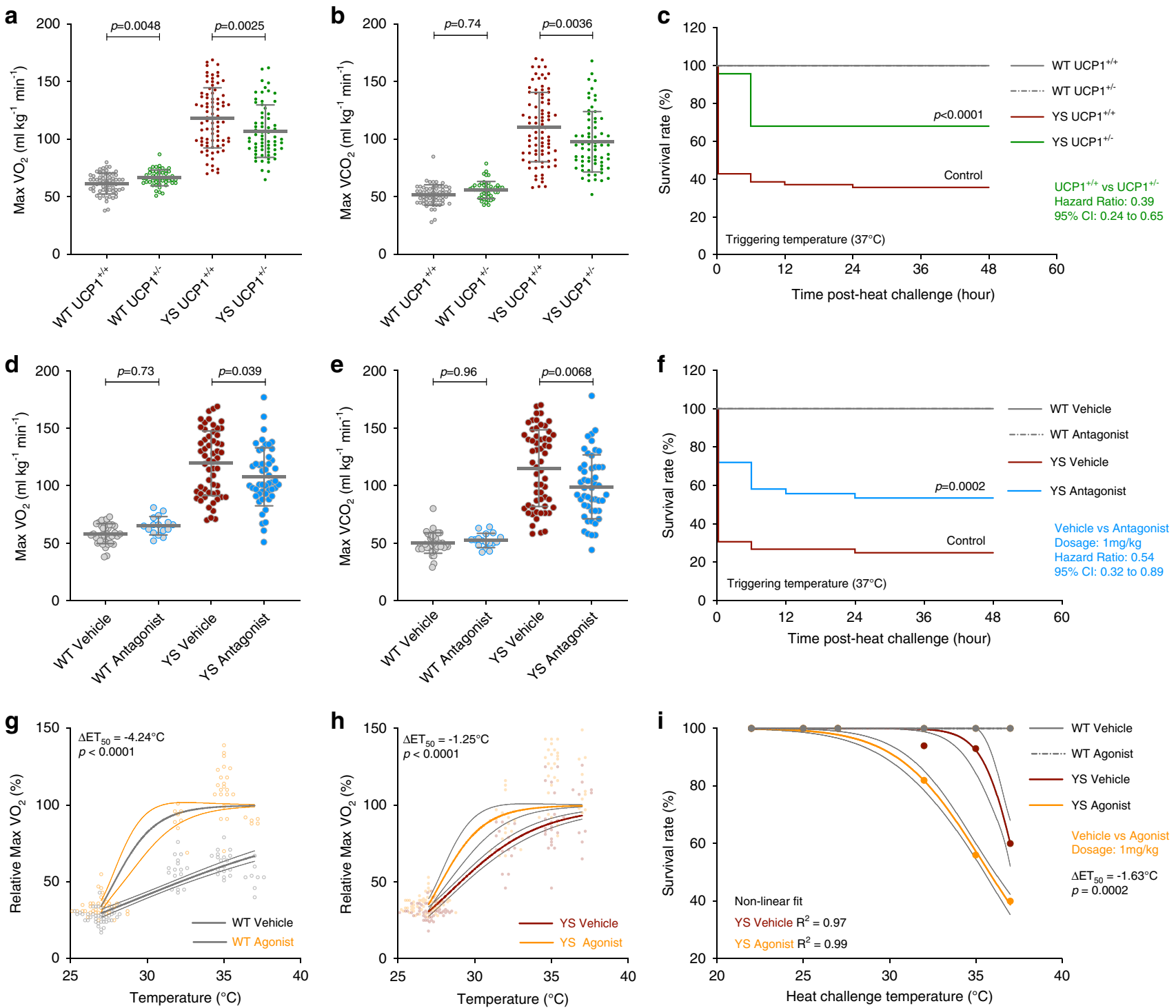

Fig. 4 Pharmacological and genetic modulation of adipose tissue thermogenic activity alters heat sensitivity of $\mathbf{Y 5 2 4 S}$ mice. a, b MaxVO $\mathrm{M}_{2}(\mathbf{a})$ and $\operatorname{maxVCO}_{2}(\mathbf{b})$ of WT $(n=108)$ and YS $(n=146)$ mice with or without heterozygous genetic ablation of the mitochondrial uncoupling protein (Ucp1WT/null) during acute heat challenge at $37^{\circ} \mathrm{C}$. c Kaplan-Meier analysis of the survival rate of WT $(n=108)$ and YS mice $(n=146)$ with or without Ucp1-ablation (heterozygous) after acute heat challenge. d, e Maximal $\mathrm{O}_{2}$ consumption (maxVO $\mathrm{O}_{2}$ d) and $\mathrm{CO}_{2}$ production $\left(\operatorname{maxVCO} \mathrm{C}_{2}\right.$ e) rate of WT $(n=53)$ and $\mathrm{YS}$ $(n=108)$ mice pretreated with $\beta 3$-adrenergic receptor $\left(\beta_{3} A R\right)$ antagonist $(L 748337,1 \mathrm{mg} / \mathrm{kg})$ or vehicle control during acute heat challenge at $37^{\circ} \mathrm{C}$. f Kaplan-Meier analysis of the survival rate of WT $(n=53)$ and YS mice $(n=108)$ pretreated with $\beta_{3}$ AR antagonist or vehicle control after acute heat challenge. $\mathbf{g}$, $\mathbf{h}$ Heat sensitivity of WT mice $(n=76, \mathbf{g})$ and YS mice $(n=106, \mathbf{h})$ pretreated with $\beta_{3}$ AR agonist (BRL37344, $\left.1 \mathrm{mg} / \mathrm{kg}\right)$ or vehicle control as measured by half-maximal effective temperature $\left(E T_{50}\right)$ on $\mathrm{O}_{2}$ consumption rate for mice during acute exposure to various temperatures. $\mathbf{i} E f f e c t$ of $\beta_{3} A R$ agonist on heat sensitivity of YS mice $(n=106)$ as measured by $\mathrm{ET}_{50}$ on survival rate of mice after acute exposures. All mice were within the controlled age range $(8.8 \pm 1.0$ week old $)$ at the time of study. $P$ values are indicated as analyzed by ordinary one-way analysis of variance (ANOVA) with Tukey's multiple comparisons test $(\mathbf{a}, \mathbf{b}, \mathbf{d}, \mathbf{e})$, and Mantel-Cox log-rank test $(\mathbf{c}, \mathbf{f})$, and F-test for differential $\mathrm{ET}_{50}$ of nonlinear regression with variable slope $(\mathbf{g}-\mathbf{i})$. Effects on heat sensitivity alteration in mice are established by comparing littermates of the same genotype with or without the genetic (a-c) or pharmacological (d-i) interventions. All statistical tests are two-sided. Data are represented as mean \pm standard deviation (a, b, d, e), or asymmetrical $95 \%$ confidence non-linear best-fit curve (g-i). Source data are provided as a source data file.

UCP1-intact YS littermate controls. YS mice completely devoid of $\mathrm{UCP} 1$ (YS/Ucp1 $1^{-/}$) also exhibited a significant improvement in survival but were not further protected compared to heterozygous $\mathrm{YS} / \mathrm{Ucp}^{+/-}$mice (Supplementary Fig. 6c-e). These studies demonstrate that UCP1-dependent thermogenesis contributes to the heat response of the YS mice.

Brown fat is heavily innervated by sympathetic nerves, and responds to cold-sensing mechanisms in the central nervous system via the abundantly expressed $\beta_{3}$-adrenergic receptors $\left(\beta_{3} \mathrm{AR}\right)^{52}$. We pharmacologically modulated the UCP1 activity using sympathomimetic agents specific to brown and beige fat selective $\beta_{3} \mathrm{AR}$. We found that acute administration of a $\beta_{3} \mathrm{AR}$ antagonist $(\mathrm{L} 748337,1 \mathrm{mg} / \mathrm{kg})^{53}$ significantly decreased the hypermetabolic response (Fig. 4d, e) and improved the survival of the YS mice compared to vehicle-treated YS littermate controls (Fig. 4f). In contrast, the administration of a $\beta_{3} \mathrm{AR}$ agonist $(B R L 37344,1 \mathrm{mg} / \mathrm{kg})^{53}$ resulted in a marked sensitization of mice to heat as assessed by changes in maximal $\mathrm{VO}_{2}$ in mice exposed at different temperatures (Fig. $4 \mathrm{~g}, \mathrm{~h}$ ). BAT activation with $\beta_{3} \mathrm{AR}$ agonist reduced the half-maximal effective temperature $\left(\mathrm{ET}_{50}\right)$ for 
the increase in $\mathrm{VO}_{2}$ in both WT (Fig. 4g) and YS mice (Fig. 4h) compared to vehicle-treated littermate controls, despite the intrinsically high heat sensitivity of YS mice at baseline. Notably, the $\beta_{3} \mathrm{AR}$ agonist significantly decreased $\mathrm{ET}_{50}$ for survival of the YS mice after the heat exposure (Fig. 4i). The effects of brown fat activation were also confirmed in YS mice treated with an alternative $\beta_{3} \mathrm{AR}$ agonist (CL316243, $1 \mathrm{mg} / \mathrm{kg}$ ), which showed significantly exacerbated heat-induced hypermetabolic response even at modest sub-triggering temperatures (Supplementary Fig. 6f, g).

To test the possibility that the $\beta_{3} \mathrm{AR}$ agonists and antagonists were altering RYR1 activity in skeletal muscle, we tested the effects of a $\beta_{3} \mathrm{AR}$ agonist (CL $316,243,10 \mu \mathrm{M}$ ) and a $\beta_{3} \mathrm{AR}$ antagonist (SR 59230A, $10 \mu \mathrm{M})$ on heat-induced increases in resting $\mathrm{Ca}^{2+}$ levels in flexor digitorum brevis (FDB) fibers and on heat-induced increases in basal tension in soleus muscles (Supplementary Fig. 6h-j). Treatment of FDB fibers with either $\beta_{3} \mathrm{AR}$ agonist or antagonists did not significantly alter the enhanced temperature-dependent increase in resting $\mathrm{Ca}^{2+}$ in FDB fibers from the YS mice (Supplementary Fig. 6h). In addition, neither $\beta_{3} \mathrm{AR}$ agonists nor $\beta_{3} \mathrm{AR}$ antagonists altered elevation in basal tension at $37^{\circ} \mathrm{C}$ in muscle from YS compared to WT mice (Supplementary Fig. 6i, j). These findings suggest $\beta_{3} \mathrm{AR}$ modulators alter temperature sensitivity of the YS and WT mice primarily via their effects on brown fat rather than on skeletal muscle.

Recent studies have shown that non-shivering thermogenesis (NST) also occurs in skeletal muscle and involves sarcolipin (SLN) uncoupling of $\mathrm{Ca}^{2+}$ uptake via the SR/ER Ca ${ }^{2+}$ ATPases (SERCA) from ATP hydrolysis, leading to increased heat production and decreased $\mathrm{Ca}^{2+}$ uptake into the $\mathrm{SR}^{27-29,54,55}$. As we have previously demonstrated ${ }^{56,57}, \mathrm{Ca}^{2+}$ uptake into the $\mathrm{SR}$ at room temperature, assessed by rate of return of cytosolic $\mathrm{Ca}^{2+}$ to baseline, was not decreased in FDB fibers from YS compared to WT mice, suggesting that the ability of SERCA to pump $\mathrm{Ca}^{2+}$ is not inhibited in fibers from YS compared to WT mice. In addition, we found no differences in $\operatorname{Sin}$ mRNA levels in the soleus or EDL muscles of YS compared to WT mice (Supplementary Fig. 6k). However, consistent with compensatory upregulation of $\operatorname{Sin}$ in UCP1-deficient mice ${ }^{54}, \operatorname{Sin}$ mRNA was significantly upregulated in the muscles of the WT/Ucp $1^{+/-}$and $\mathrm{YS} / \mathrm{Ucp} 1^{+/}$- mice relative to UCP1-intact littermate controls (Supplementary Fig. 6k). While we cannot eliminate a possible contribution of NST in skeletal muscle, our results suggest that brown fat thermogenesis is a greater contributor to the heat sensitivity of the YS mice.

Adaptive thermogenesis alone is not causative of the heat sensitivity of the YS mice, but rather, further sensitizes the YS mice to heat by increasing basal body temperature. When treated with dantrolene, which blocks SR $\mathrm{Ca}^{2+}$ release, the YS mice respond like WT mice and did not die following heat challenge at triggering temperature $\left(37^{\circ} \mathrm{C}\right)$, even if $\mathrm{BAT}$ is activated with a $\beta_{3} \mathrm{AR}$ agonist (Supplementary Fig. 6l). However, we found a small but significant increase in the $\beta_{3} \mathrm{AR}$ agonist-induced hypermetabolic response in YS mice compared to their littermate controls (Supplementary Fig. 6m), suggesting a greater adipose tissue thermogenic capacity in YS mice.

Increased BAT activity and white adipose tissue browning in YS mice. We found that male YS mice had significantly greater BAT mass in the interscapular region (iBAT) than their male WT littermates (Fig. 5a, b). In contrast, female YS mice had the same amount of BAT mass as their female WT littermates (Fig. 5c). To quantitatively assess the activity of brown fat in mice, we used integrated positron-emission tomography and computed tomography (PET/CT) functional imaging, which maps the metabolic activity by measuring the uptake of the glucose analog ${ }^{18}$ F-fluorodeoxyglucose (18F-FDG) systemically in tissues. The mice were precooled at $4{ }^{\circ} \mathrm{C}$ for $4 \mathrm{~h}$ prior to imaging to enable detection of $18 \mathrm{~F}-\mathrm{FDG}$ uptake. The active volume and total activity for 18F-FDG in and around the interscapular region were significantly higher in the YS mice compared to their WT littermate controls (Fig. 5d, e, Supplementary Fig. 7a-d) with no difference in lean mass (Supplementary Fig. 7e). Moreover, as indicated by pharmacokinetic analysis of $18 \mathrm{~F}-\mathrm{FDG}$ uptake (Supplementary Fig. $7 f-h$ ), we found a faster rate of decline in the FDG signal in YS mice. Because of the combined effect of precooling, which activates BAT, and isoflurane, a volatile anesthetic which can trigger an $\mathrm{MH}$ response, a portion of the YS mice had $\mathrm{MH}$ responses and died during the imaging (Supplementary Fig. 7i). Despite isoflurane effects on FDG uptake arising from the $\mathrm{MH}$ response of some of the mice, we detected a significant increase of total iBAT activity in surviving YS mice, suggesting that the detected iBAT activity is an underestimate of the baseline level without the isoflurane exposure. Consistent with the pediatric predominance in brown fat activity in humans and the associated enhanced heat sensitivity in pediatric individuals with RYR1 variants associated with MHS, we found that brown fat metabolic activity was the highest in young YS mice and declined gradually with age in both WT and YS mice (Fig. 5f-i). The increased BAT activity was also consistent with an increase in UCP1 expression in iBAT (Fig. 5j).

Browning of subcutaneous white adipose tissue (WAT) also contributes to thermogenesis in mice and humans ${ }^{58,59}$. We found increased multilocular adipocytes in the subcutaneous inguinal WAT (iWAT) of the YS mice compared to that of WT littermate controls (Fig. 5k), resembling the metabolically more active brown adipocytes. Despite the variable UCP1 expression among mice and the tissue heterogenicity of UCP1 within iWAT (Supplementary Fig. 8a, b), we found the amount of UCP1 was increased in YS compared to WT littermates at both protein and mRNA levels (Fig. 5l, Supplementary Fig. 8c). Browning of the white fat in YS mice was further supported by the significant elevations in PPAR- $\gamma$ coactivator- 1 alpha (PGC1 $\alpha$ ) and mitochondrial markers, including cytochrome C (CYC), mitofusin-2 (MFN2), sirtuin-3 (SIRT3), and manganese superoxide dismutase (MnSOD) in the iWAT of YS mice compared to that of WT littermates (Supplementary Fig. 8d, e). These results indicate that brown fat activity and white fat browning are both increased in YS mice.

Circulating lactate is increased in the YS mice. The skeletal muscle $\mathrm{Ca}^{2+}$ release channel (RYR1) is central to muscle excitation-contraction coupling. To explore the mechanism by which a mutation in Ryrl alters the amount and activity of BAT, we assessed the levels of a wide range of circulating factors in the serum or urine of YS mice compared to their WT littermate controls. We did not detect significant changes in most known browning factors, including fibroblast growth factor 21 (FGF21), thyroid hormone $\left(\mathrm{T}_{4}\right)$, or irisin (Fig. 6a). However, we found a significant increase in circulating lactate (Fig. 6a). Specifically, we found lactate levels were substantially elevated in the serum of YS compared to WT mice both during the day and the night (Fig. 6b) despite significant circadian fluctuations in tail artery blood lactate levels (Supplementary Fig. 9a-c).

Lactate is the end product of glycolysis and increased circulating levels of lactate are associated with increased muscle glycogen breakdown with exercise ${ }^{60}$. Increased intracellular $\mathrm{Ca}^{2+}$ due to a leaky RYR1 channel can activate multiple $\mathrm{Ca}^{2+}$ sensitive pathways including glycogenolysis via $\mathrm{Ca}^{2+}$-bound calmodulin 


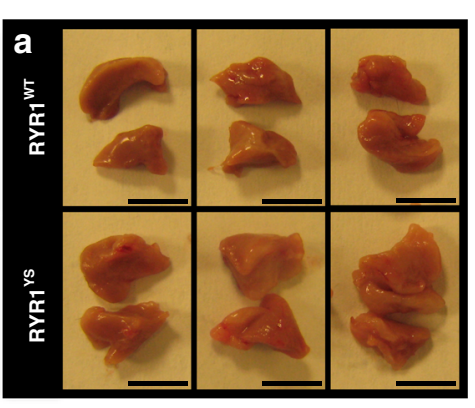

Interscapular brown adipose tissue (iBAT) Gross anatomy (male)
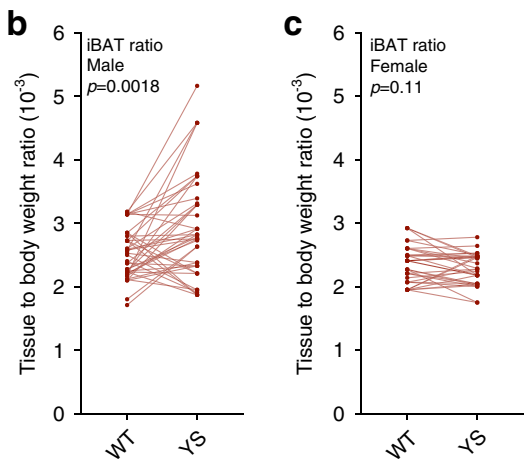
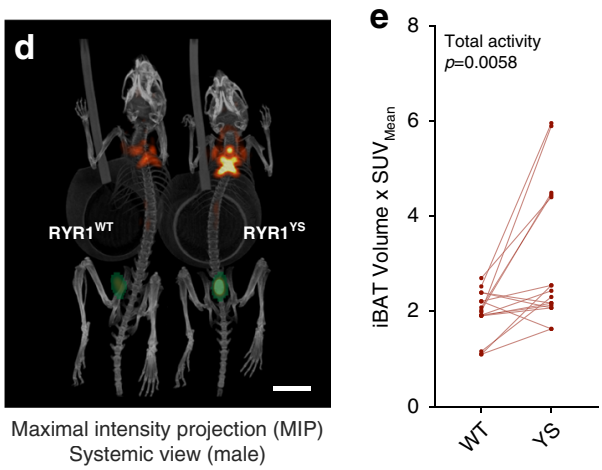
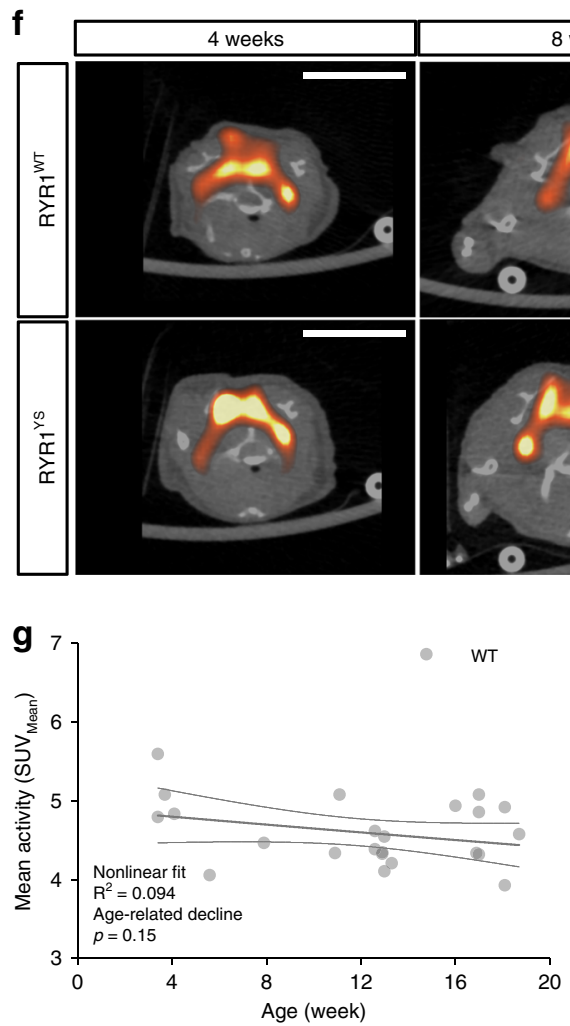

j
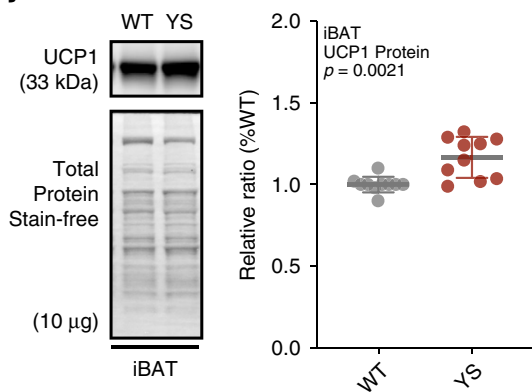
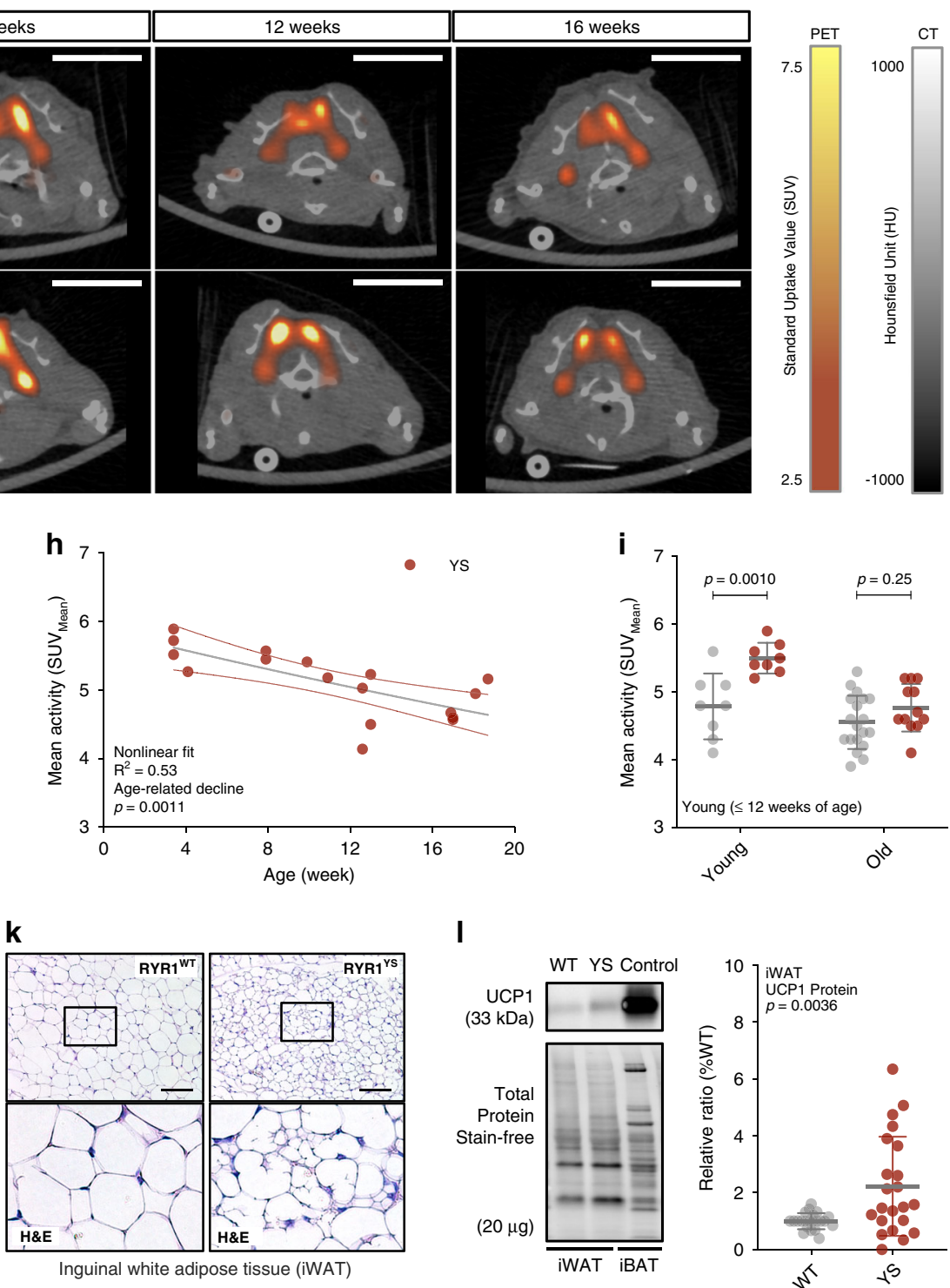

( $\mathrm{CaCaM})$, which acts as the $\delta$ subunit of glycogen phosphorylase kinase (PHK) in muscle ${ }^{61}$. To demonstrate that the elevated circulating lactate is the result of skeletal muscle glycogenolysis and glycolysis, we assayed gastrocnemius muscle and found that blood lactate inversely correlated with muscle glycogen (Fig. 6c) and both glycogen and glucose levels were significantly decreased in muscle of the YS compared to WT mice in the absence of exercise (Fig. 6d, e). In contrast to the decreased levels of glucose and glycogen in muscle, we detected a significant increase in hepatic glucose levels with no difference in blood glucose or hepatic glycogen in the YS mice, indicating normal hepatic gluconeogenesis following the uptake of circulating lactate into the liver (Supplementary Fig. 9d-g). These results suggest that the primary source of the elevated circulating lactate in YS mice is skeletal muscle glycogenolysis and glycolysis, and not a defect in hepatic lactate clearance. 
Fig. 5 Elevated brown adipose tissue thermogenic capacity and white adipose tissue browning in Y524S mice. a Gross anatomy for the interscapular brown adipose tissue (iBAT) from WT and YS littermates. b, c Tissue to body weight ratio of iBAT resected from littermate pairs of WT and YS in male $(n=42$ pairs, $\mathbf{b})$ and female $(n=36$ pairs, $\mathbf{c})$ mice. $\mathbf{d}$ Representative PET-CT scan of WT and YS littermate. e Quantification of total iBAT activity in WT and YS littermates $(n=16$ pairs). $\mathbf{f}$ Representative PET-CT scans from the interscapular region of WT and YS mice from various age groups. $\mathbf{g}-\mathbf{i}$ Age related decline of body weight-adjusted total iBAT activity in WT $(n=28, \mathbf{g})$ and YS $(n=17, \mathbf{h})$ mice, and comparison between WT and YS within age groups (i). $\mathbf{j}$ Relative UCP1 protein levels in iBAT from WT $(n=10)$ and YS $(n=10)$ littermates. $\mathbf{k}$ H\&E stain images of subcutaneous inguinal white adipose tissue (iWAT) from WT and YS littermate. Morphological changes are consistent across three independent littermate pairs. I Relative protein levels of UCP1 in iWAT from WT $(n=22)$ and YS $(n=22)$ littermates, using iBAT as a positive control. $P$ values are indicated as analyzed by paired $t$ test $(\mathbf{b}$, $\mathbf{c}$, e), $F$-test for deviation from zero-rate constant of nonlinear regression $(\mathbf{g}, \mathbf{h})$, and two-way ANOVA with Sidak's multiple comparisons test (i), and Welch's $t$ test $(\mathbf{j}, \mathbf{I})$. All statistical tests are two-sided. $R^{2}$ values are indicated to quantify goodness-of-fit to nonlinear regression with variable slope $(\mathbf{g}, \mathbf{h})$. Data are

represented as mean \pm standard deviation $(\mathbf{i}, \mathbf{j}, \mathbf{I})$, or asymmetrical $95 \%$ confidence intervals $(\mathrm{Cl})$ from nonlinear best-fit curve $(\mathbf{g}$, $\mathbf{h})$. Mice were within the controlled age range (male: $12.0 \pm 0.3$-week-old (b), and female: $11.9 \pm 0.3$ week old (c)) at the time of study, except for the age-dependent experiments (g-i). Display ranges of standard uptake value (SUV) for PET and Hounsfield unit (HU) for CT are as indicated (f). Scale bars are $5 \mathrm{~mm}$ from the gross anatomy images (a), $10 \mathrm{~mm}$ from the PET-CT scans (d, f), and $100 \mu \mathrm{m}$ from the histological images (k). Source data are provided as a source data file.

Increases in cytosolic $\mathrm{Ca}^{2+}$ levels also activate the SERCA to restore SR luminal $\mathrm{Ca}^{2+}$ levels and actomyosin ATPase for myofilament cross-bridge cycling functions. Glycolysis can be activated by the energy-sensing AMP kinase (AMPK) in response to increased energy demand ${ }^{62}$. To probe muscle energetics in the YS mice, we used ${ }^{31} \mathrm{P}$ nuclear magnetic resonance (NMR) spectroscopy to detect changes in phosphocreatine (PCr), ATP, and inorganic phosphate $(\mathrm{Pi})$ in the hindlimbs of WT and YS littermate mice in vivo (Fig. 6f). PCr phosphorylates ADP to ATP to prevent major changes in muscle ATP levels ${ }^{63}$. We found a significant decrease in the $\mathrm{PCr} / \mathrm{Pi}$ ratio in $\mathrm{YS}$ mice (Fig. 6g, Supplementary Fig. 9h, i) in the absence of a net change in ATP (Supplementary Fig. 9j), suggesting that $\mathrm{PCr}$ is efficiently replacing utilized ATP. ATP utilization increases AMP/ATP ratios which allosterically enhance the phosphorylation of Thr172 in the AMPKa subunit ${ }^{64}$. The $\mathrm{Ca}^{2+} /$ calmodulin-dependent protein kinase kinase $\beta(\mathrm{CAMKK} \beta)$, activated by increased cytosolic $\mathrm{Ca}^{2+}$ and $\mathrm{Ca}^{2+} \mathrm{CaM}$ and by phosphorylation ${ }^{65}$, phosphorylates Thr172 on AMPKa ${ }^{66-68}$. Consistent with the increased resting cytosolic $\mathrm{Ca}^{2+}$ levels, CaMKK2 phosphorylation was increased in the muscle of the YS mice (Supplementary Fig. 10a, b). Using reverse phase protein arrays (RPPA), we found a substantial increase in pT172-AMPK/AMPK in soleus, EDL, and diaphragm of the YS compared to WT mice (Fig. $6 \mathrm{~h}-\mathrm{j}$, Supplementary Data 3) under baseline conditions. AMPK is activated by muscle contraction and exercise ${ }^{69}$. Increased AMPK activation suggests that muscles of the YS mice have increased metabolic activity, possibly due to transient muscle contractures. Such an increase in muscle activity would lead to increased lactate, even in the absence of elevated environmental heat.

Since norepinephrine and epinephrine activate BAT thermogenesis $^{70}$, we measured the levels of epinephrine and norepinephrine output in the urine of the YS and WT mice. Consistent with the positive association between circulating lactate and catecholamine levels in humans ${ }^{71-73}$, we detected a significant increase in the total 24-h excretion of epinephrine in the urine of YS mice compared to that of WT littermates with no difference in norepinephrine (Supplementary Fig. 10c, d). As a sympathetic activator, epinephrine increases both adipose tissue thermogenesis and skeletal muscle force production ${ }^{74}$, thereby amplifying the effect of the Ryrl mutation on both lactate production and thermogenesis.

Lactate increases brown/beige adipogenesis and UCP1 levels in brown and WAT. Both lactate and epinephrine elevate UCP1 levels in adipocytes ${ }^{75,76}$. Exercise also increases adipocytes progenitor populations in brown fat $^{77}$. However, the exact mechanism of brown adipogenesis induced specifically by lactate is not known. To evaluate the effect of lactate on brown adipogenesis, we performed brown adipogenic assays on isolated primary stromal-vascular fraction (SVF) cells from iBAT isolated from pups at post-natal day 10 (P10). These cells were incubated with or without lactate $(10 \mathrm{mM})$ and with and without an inhibitor of monocarboxylate transporters $1 / 2$ (MCT1/2), ARC155858 (AR-C, $0.1 \mu \mathrm{M}$ ). We found that UCP1 protein levels in differentiated SVF cells were significantly higher in cells treated with lactate compared to vehicle-treated controls, and this increase was prevented by AR-C (Fig. $7 \mathrm{a}, \mathrm{b})$. We also detected a significant increase in UCP1 levels in a mitochondrial fraction isolated from differentiated brown SVF cells and this increase was again blocked by AR-C (Fig. 7c, d). Lactate influx also transcriptionally increased brown adipogenic genes including Ucp1, Ppargcla, and Cidea (Supplementary Fig. 11a-c). These findings suggest that lactate influx via MCTs is crucial for the lactate driven increase in $U c p 1$ expression in cells differentiated from preadipocytes from BAT SVF.

As discussed above, YS mice displayed increased mass and volume of interscapular brown fat compared to their WT littermates (Fig. 5, Supplementary Fig. 7). We did not detect a significant difference in adipocyte size (Supplementary Fig. 11d-f), suggesting hyperplasia rather than hypertrophy of brown adipocytes in the YS mice. To determine if lactate was also contributing to hyperplasia of brown fat, we performed cell cycle analysis of proliferating brown fat SVF cells from WT mice by flow cytometry. Because these precursor cells in brown fat SVF could be a mixture of myogenic and non-myogenic origins, we designate them as brown/beige preadipocytes. Brown/beige preadipocytes in SVF were identified as double positive cells for preadipocyte marker platelet-derived growth factor receptor a (PDGFRa) and early B cell factor (EBF2), a selective marker for both brown and beige preadipocytes ${ }^{78}$. We found that brown/ beige preadipocytes (PDGFRa ${ }^{+} / \mathrm{EBF}^{+}$) were more proliferative than other cells in SVF (Supplementary Fig. 11g, h). Lactate treatment significantly increased the proportion of brown/beige preadipocytes in proliferative S/G2 phase and decreased proportion in quiescence $\mathrm{G} 1$ phase, and this proliferative effect of lactate was abolished by the MCT1/2 inhibitor (Fig. 7e, f). Consistent with the proliferative effect of lactate, we found an increase in $\mathrm{EBF}^{+}$frequency in the $\mathrm{PDGFR}^{+}$preadipocytes fraction in brown SVF cells from P2.5 YS neonates compared to their WT littermates (Fig. 7g, h). The PDGFRa ${ }^{+}$preadipocytes from YS mice were also significantly smaller as indicated by the forward scatter (FSC) of flow cytometry, possibly due to active cell division (Fig. 7i). These findings suggest that lactate increases the proliferation of brown/beige preadipocytes in SVF, which is likely to underlie the increase in brown fat mass in the YS mice.

As shown in Fig. 5, we also detected an increase in UCP1 levels in subcutaneous white fat of adult YS mice compared to their WT 

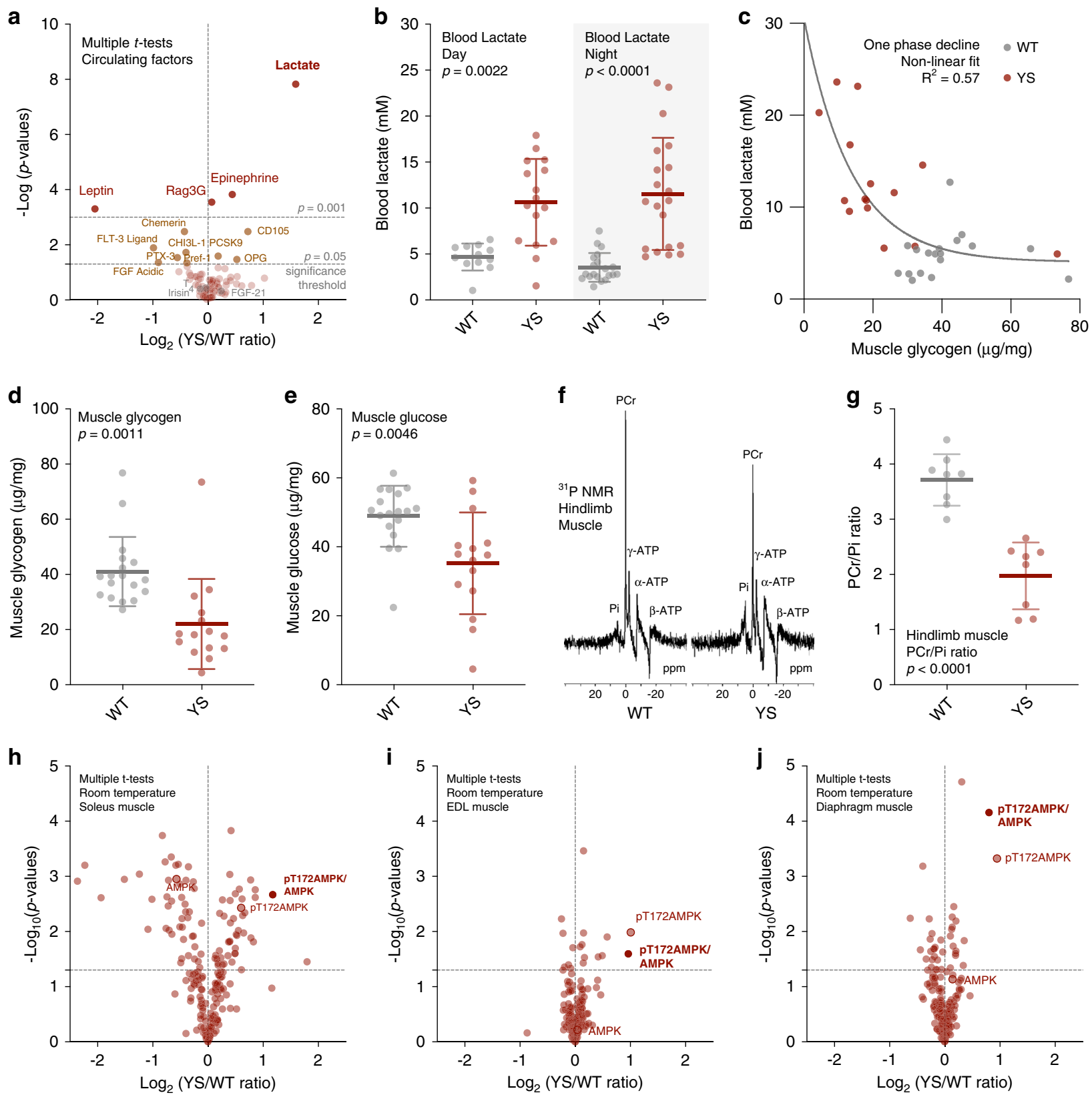

Fig. 6 Increased circulating levels of skeletal muscle-derived lactate in the Y524S mice. a Volcano plot comparing the levels of circulating factors in WT $(n=4)$ and YS $(n=4)$ littermates. b Blood lactate concentration of WT and YS littermates as measured in filtered serum collected during day (WT $n=12$, YS $n=16)$ and night (WT $n=20$, YS $n=20$ ) time. c Relationship of gastrocnemius muscle glycogen and blood lactate levels in WT ( $n=18)$ and YS ( $n=$ 15) mice. d, e Muscle glycogen (d) and glucose (e) concentration as measured in gastrocnemius muscle isolated from WT $(n=18)$ and YS $(n=15)$ littermates. f Representative ${ }^{31} \mathrm{P}$ nuclear magnetic resonance (NMR) spectra of hindlimb muscles measured in vivo from WT and YS littermate. $\mathbf{g}$ Quantification of phosphocreatine to inorganic phosphate ratio $(\mathrm{PCr} / \mathrm{Pi})$ based on analysis of the ${ }^{31} \mathrm{P}$ NMR spectra from WT $(n=8)$ and YS $(n=8)$ hindlimb muscles. h-j Volcano plot comparing the level of proteomic changes in soleus (h), EDL (i), and diaphragm (j) muscle of WT ( $n=3$ ) and YS ( $n=$ 3) littermates. $P$ values are indicated as analyzed by two-side unpaired $t$ test without adjustment for multiple comparisons (a, $\mathbf{h}-\mathbf{j}$ ), ordinary one-way analysis of variance (ANOVA) with Tukey's multiple comparisons test (b), and Welch's $t$ test (d, e, g). All statistical tests are two-sided. $R^{2}$ values are indicated to quantify goodness-of-fit to nonlinear regression with variable slope (c). Data are represented as mean \pm standard deviation (b, $\mathbf{d}, \mathbf{e}, \mathbf{g}$ ). Mice were within the controlled age range $(10.0 \pm 1.8$ week old $)$ at the time of study. Source data are provided as a source data file.

littermates. In addition to the effect of lactate on brown fat SVF cells, we tested the effect of lactate on SVF cells isolated from white fat and cultured 3T3L-1 preadipocytes. We found that lactate upregulated the expression of UCP1 and other browning markers across all systems, despite a variable expression at baseline among different sources of preadipocytes (Fig. 8a-d, Supplementary Fig. 12a-c). Again, the effect of upregulation of UCP1 levels was abolished with MCTs inhibition (Fig. 8a-d).
These findings suggest that lactate influx via MCTs induces brown adipogenesis in both brown and subcutaneous WAT.

Finally, to determine if lactate is the primary circulating factor which induces brown adipogenesis in YS mice, we tested serum from WT and YS mice on 3T3L-1 preadipocytes and found that the serum from YS mice significantly increased the expression of UCP 1 compared to serum from WT littermate controls (Fig. 8e, f). To determine if this effect of YS serum on UCP1 

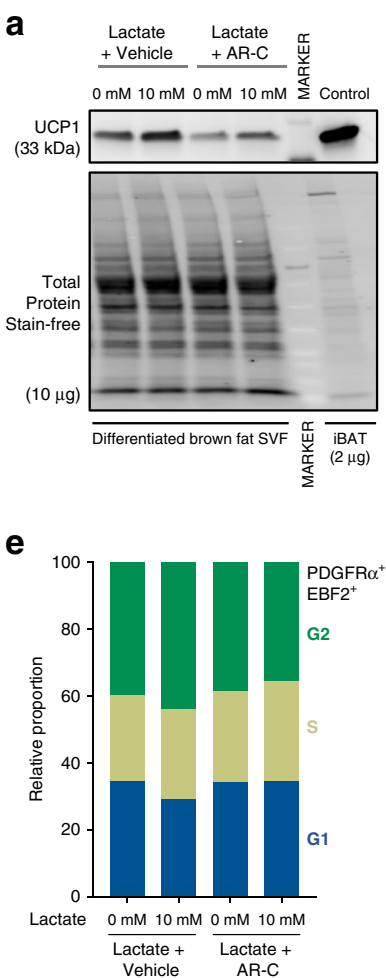

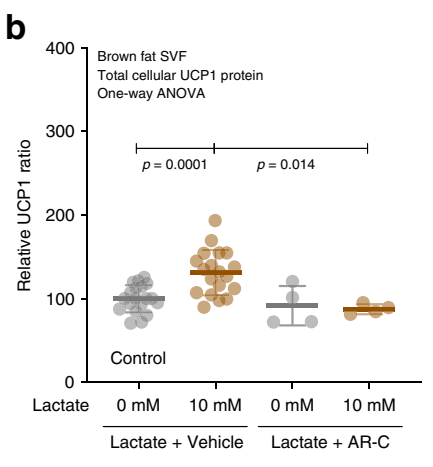

$\mathbf{f}$

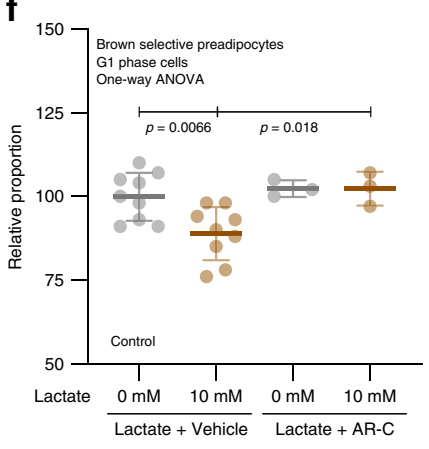

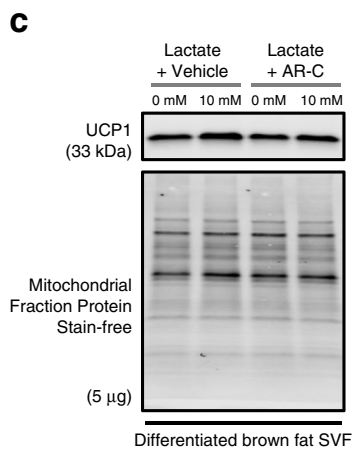
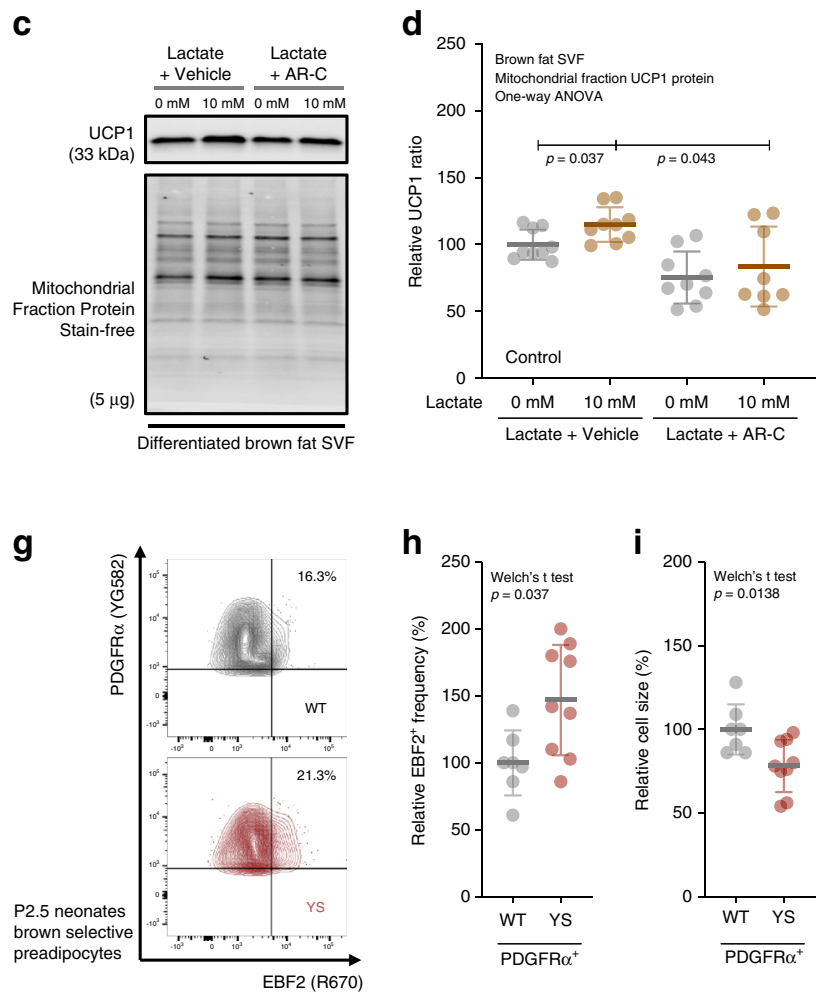
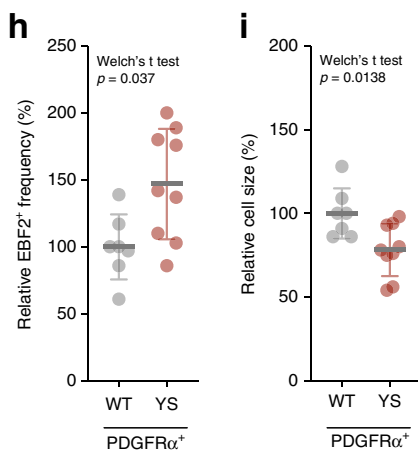

Fig. 7 Lactate promotes brown adipogenesis in brown preadipocytes. a, b Representative immunoblots (a) and relative protein levels (b) for

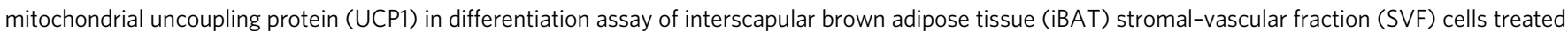
with vehicle control $(n=19)$, lactate $(n=19)$, monocarboxylate transporter $($ MCT1/2) inhibitor $(n=4)$ or both $(n=4)$. c, $\mathbf{d}$ Representative immunoblots (c) and relative protein levels $(\mathbf{d})$ for UCP1 in mitochondrial fraction of differentiated iBAT SVF cells treated with vehicle $(n=9)$, lactate $(n=9)$, MCT1/2 inhibitor $(n=9)$ or both $(n=8)$. One data point (Lactate + ARC $=182.6 \%$ of control) identified as a statistical outlier (more than $2.04 \sigma$ above the group mean) was excluded from the analysis based on the Grubb's method. e, $\mathbf{f}$ Representative cell cycle distributions (e) and relative proportions (f) of $\mathrm{G} 1$ phase brown-selective preadipocytes in proliferation assay of iBAT SVF cells treated with vehicle $(n=9)$, lactate $(n=9)$, MCT1/2 inhibitor $(n=3)$ or both $(n=$ 3). $\mathbf{g}$ Representative contour plots of platelet-derived growth factor receptor $\alpha$-positive (PDGFR $\alpha^{+}$) preadipocytes in primary iBAT SVF cells isolated from P2.5 neonates of WT and YS littermate. $\mathbf{h}$, i Relative early B cell factor-2-positive (EBF2 ${ }^{+}$) frequency (h) and relative cell size (forward scatter, $\mathbf{i}$ ) in PDGFR $\alpha^{+}$preadipocytes in primary iBAT SVF cells from P2.5 neonates of WT $(n=7)$ and YS $(n=9)$ littermates. $P$ values are indicated as analyzed by ordinary one-way analysis of variance (ANOVA) with Dunnett's multiple comparisons test (b, d, f), and Welch's $t$ test (h, i). All statistical tests are twosided. Data are represented as mean \pm standard deviation. Relative protein levels are determined as protein levels normalized to vehicle (b, $\mathbf{d}$, f) treated controls. Relative proportions are determined as proportions normalized to the level of wild-type littermate controls (h, $\mathbf{i}$ ). Source data are provided as a source data file.

expression was primarily due to lactate, we filtered WT and YS serum to remove components larger than $10 \mathrm{kDa}$, but retain lactate. Only small fragments of muscle proteins were left in the filtered sera, but none were increased in the YS compared to WT filtered serum (Supplementary Fig. 12d). The filtered serum from YS mice enhanced UCP1 expression to a greater extent than the filtered serum from WT littermates. The increase in UCP1 was prevented by MCTs inhibition (Fig. 8g, h). Collectively, these results suggest that skeletal muscle-derived lactate is not only applicable but also central to the increased brown/beige thermogenic capacity in YS mice.

Elevated blood lactate levels in heat-sensitive MHS patients with RYR1 variants. Our findings with the YS mice raise the question of whether circulating lactate is associated with heatsensitivity in MHS patients. We compared serum lactate levels in heat-sensitive patients with RYR1 variants associated with MHS to asymptomatic carriers of the same variants and found that lactate was increased significantly in the serum of the heatsensitive patients (Fig. 9a). The lactate levels in human serum are much lower than that detected in mice, raising the question of whether the small elevations detected could induce brown adipogenesis by upregulating UCP1 in human preadipocytes. In our attempt to quantify the dosage effect of lactate induced UCP1 expression in vitro, we tested the effects of low concentrations of lactate on UCP1 expression in immortalized human brown preadipocytes (hTERT). We found that lactate optimally increased UCP1 expression in this human cell line at 1-2 mM concentration range (Fig. 9b, c), indicating that even low concentrations of lactate drive UCP1 expression. Additional studies are needed to further evaluate the role of lactate and brown fat thermogenesis in individuals with $R Y R 1$ variants associated with heat sensitivity.

\section{Discussion}

The data presented here support a model in which both skeletal muscle and brown/beige adipose tissue contribute to the enhanced sensitivity of the YS mice to heat (Fig. 9d). The YS mutation in RYR1 increases SR $\mathrm{Ca}^{2+}$ leak and cytosolic $\mathrm{Ca}^{2+}$, which further sensitizes the RYR1 channel to activators ${ }^{25}$. The magnitude of the SR $\mathrm{Ca}^{2+}$ leak is increased by temperature ${ }^{25,79}$. Additional increases in heat can lead to sustained whole body muscle contractures, rhabdomyolysis and death from heart or kidney failure in the YS mice $24,25,80$. Increased cytosolic $\mathrm{Ca}^{2+}$ at rest activates $\mathrm{Ca}^{2+}$-sensing mechanisms and leads to muscle 

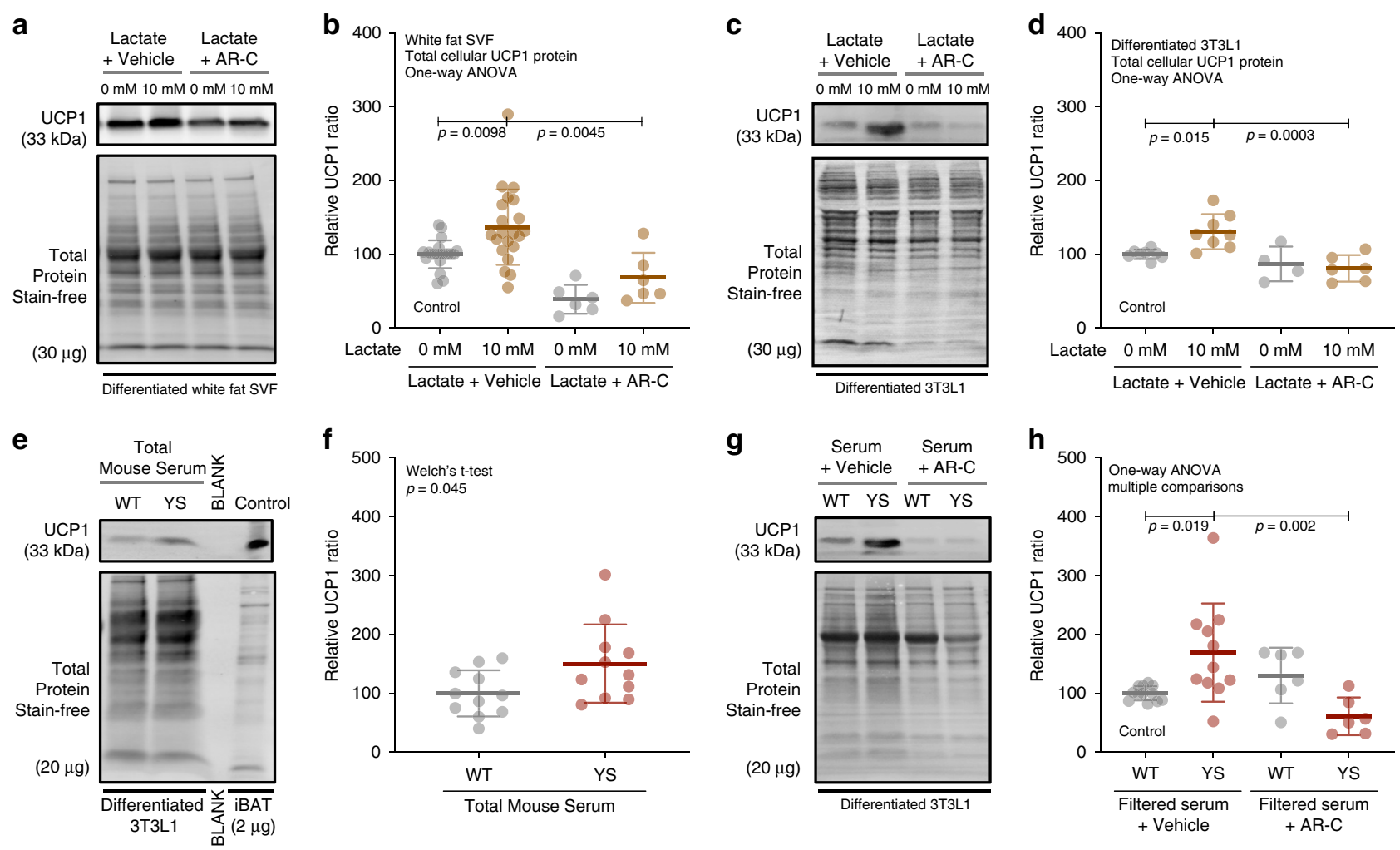

Fig. 8 Lactate promotes brown adipogenesis in white preadipocytes. a, b Representative immunoblots (a) and relative protein levels (b) for mitochondrial uncoupling protein UCP1 in differentiation assay of inguinal white adipose tissue (iWAT) SVF cells treated with vehicle $(n=21)$, lactate $(n=$ 21), MCT1/2 inhibitor $(n=6)$ or both $(n=6)$. c, d Representative immunoblots (c) and relative protein levels (d) for UCP1 in differentiation assay of $3 T 3-\mathrm{L} 1$ preadipocytes treated with vehicle $(n=8)$, lactate $(n=8), \operatorname{MCT1} / 2$ inhibitor $(n=4)$ or both $(n=6)$. e, f Representative immunoblots $(\mathbf{e})$ and relative protein levels (f) for UCP1 in differentiation assay of 3T3-L1 preadipocytes treated with unfiltered serum $(10 \%)$ from WT $(n=11)$ or YS $(n=11)$ mice. $\mathbf{g}$, $\mathbf{h}$ Representative immunoblots $(\mathbf{g})$ and relative protein levels $(\mathbf{h})$ for UCP1 in differentiation assay 3T3-L1 preadipocytes treated with $10 \mathrm{~kb}$-filtered serum (20\%) from WT and YS mice, with (WT, $n=12, Y S, n=11$ ) or without (WT, $n=6, Y S, n=6)$ the MCT1/2 inhibitor. $P$ values are indicated as analyzed by ordinary one-way analysis of variance (ANOVA) with Dunnett's multiple comparisons test (b, $\mathbf{d}, \mathbf{h}$ ), Welch's $t$ test (f). All statistical tests are two-sided. Data are represented as mean \pm standard deviation. Relative protein levels are determined as protein levels normalized to vehicle (a, $\mathbf{b})$ or wild-type mouse serum $(\mathbf{f}, \mathbf{h})$ treated controls. Source data are provided as a source data file.

glycogenolysis and glycolysis, which elevates the circulating lactate. Circulating lactate is partially cleared by the liver and used for gluconeogenesis. However, muscle lactate production is sustained by the defective RYR1 channel via the effects of cytosolic $\mathrm{Ca}^{2+}$ on muscle metabolism. Circulating lactate induces brown/ beige adipogenesis in fat by upregulating UCP1 levels. This increases the capacity of brown fat for adaptive thermogenesis systemically in the YS mice, especially upon chronic exposure to cold. Activation of BAT thermogenesis by pre-exposure to cold temperature or food intake causes a small elevation in body temperature that increases SR $\mathrm{Ca}^{2+}$ leak, creating a maladaptive feed-forward cycle of heat-induced heat response (Fig. 9d).

Pathogenic variants in the gene coding for the skeletal muscle $\mathrm{Ca}^{2+}$ release channel (RYR1) underlie both MHS and an MHassociated life-threatening response to heat ${ }^{10-13}$. In the most severe cases, both $\mathrm{MH}$ and the adverse heat response are characterized by sustained, whole body muscle contractures, leading to rhabdomyolysis and death from heart or kidney failure ${ }^{77,81}$. Responses in older adults with RYR1 pathogenic variants are frequently in the form of exercise intolerance, myalgia, muscle cramps, and rhabdomyolysis ${ }^{10-13,18,19,40,82,83}$. Life-threatening responses, however, can occur in adults with these RYR1 variants performing long duration, intense sports/exercise, or military training ${ }^{84}$. In addition, several commonly used medications (e.g., statins) have been associated with incidences of non-anesthetic $\mathrm{MH}$-like responses in these individuals ${ }^{85-87}$. Drugs that cause hyperthermia ${ }^{88}$ could potentially trigger an $\mathrm{MH}$-like episode and hence, body temperature is likely to play a critical role in the susceptibility to these MH-like responses to heat and/or exercise.

We conducted a retrospective cohort study and a systematic review to provide an up-to-date, comprehensive summary of the documented cases. As anticipated from previous reports ${ }^{7,41,89}$, we found that young age and male gender are significant risk factors for heat-sensitivity among individuals with RYR1 variants associated with MHS. Children with MHS, especially infants, are the most vulnerable to heat-induced death. Children with these pathogenic variants are at higher risk than most children when exposed to high temperatures such as being left in a hot car. However, additional studies, including longitudinal clinical studies and controlled preclinical experiments, are needed to confirm these findings and to elucidate the underlying mechanisms for the pediatric and male predominance. Nevertheless, the identified risk factors should provide insights for prevention and management of the life-threatening response to heat in MHS patients.

Consistent with the potentially lethal heat response in children with MHS, we found that the YS mice display a life-threatening response to heat that is also more severe in young mice and displays male predominance. Since adaptive thermogenesis, the finely regulated bioenergetic process that produces heat in response to changes in environmental temperature or diet $^{90-92}$, plays a crucial role in the regulation of body temperature, we 
a

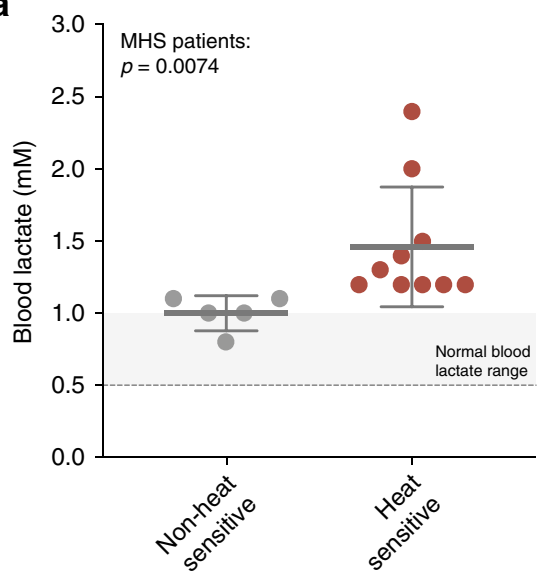

b

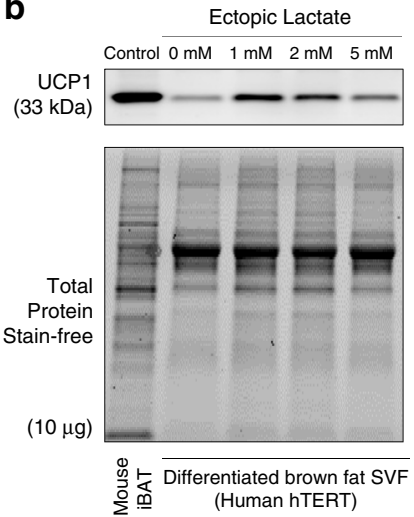

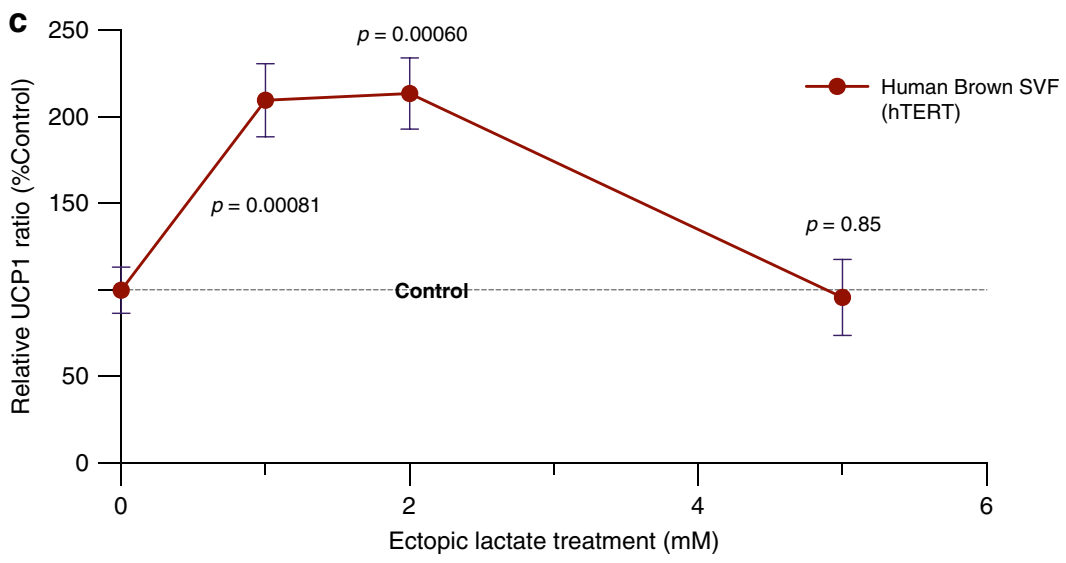

d

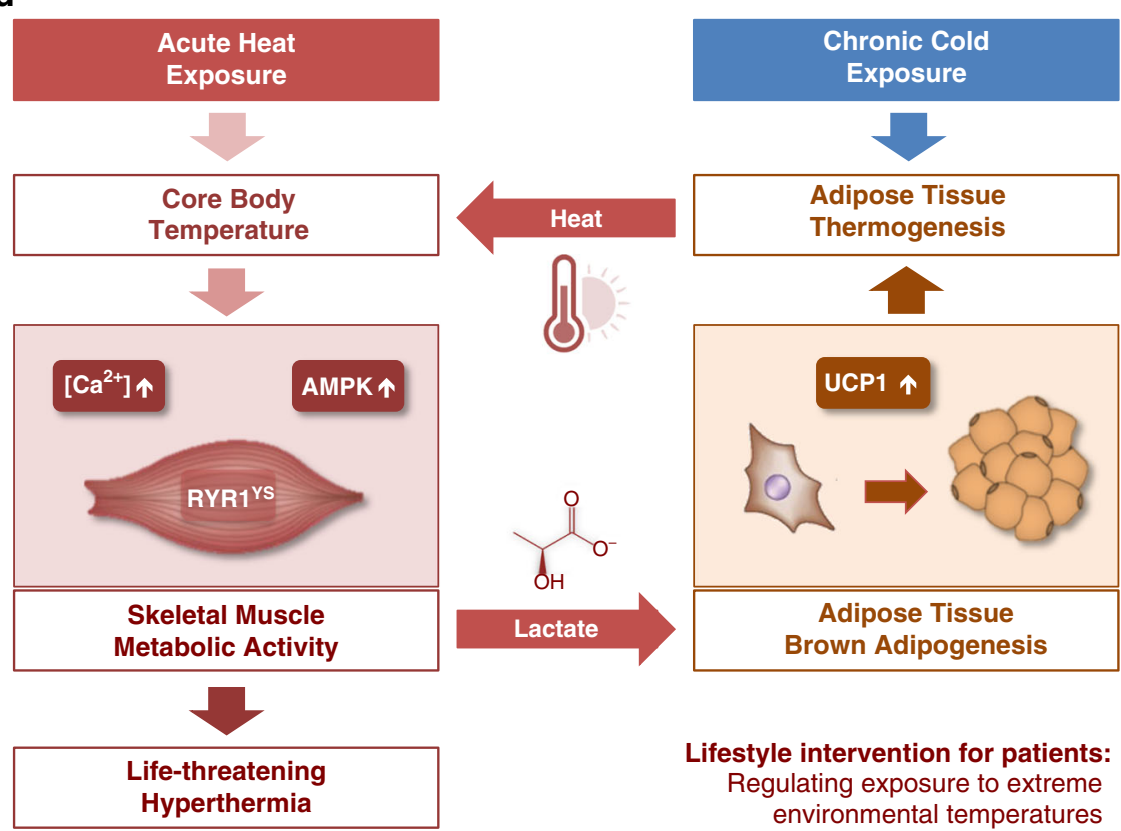

Fig. 9 Increased blood lactate in heat-sensitive MHS patients and its effect on human preadipocyte brown adipogenesis. a Blood lactate concentration of non-heat sensitive $(n=5)$ and heat-sensitive $(n=10)$ MHS patients carrying RYR1 variants. $\mathbf{b}$, $\mathbf{c}$ Representative immunoblots (b) and relative protein levels (c) for the mitochondrial uncoupling protein (UCP1) in differentiation assay of immortalized human preadipocytes from stromal-vascular fraction of brown adipose tissue treated with vehicle control and different dose of ectopic lactate $(n=5$ each). $\mathbf{d}$ Proposed model of an adaptive thermogenesis enhanced feed-forward cycle of heat-induced heat response in susceptible patients. $P$ values are indicated as Welch's $t$ test (a, c). All statistical tests are two-sided. Data are represented as mean \pm standard deviation (a) and mean \pm standard error of the mean (c). Relative protein levels are determined as levels normalized to the level of vehicle-treated controls (c). Source data are provided as a source data file. 
assessed the contribution of adaptive thermogenesis to the heat sensitivity of the YS mice. BAT and skeletal muscle are the principal sites for adaptive thermogenesis. Our rationale to investigate a role for adaptive thermogenesis in the response to heat was that young children have more BAT and rely more on adaptive thermogenesis to maintain body temperature compared to adults ${ }^{93,94}$.

To evaluate the contribution of brown fat thermogenesis to the heat sensitivity of the YS mice, we used both genetic and pharmacological modulation of BAT. While the primary cause of the heat response of the YS mice is a temperature-dependent increase in cytoplasmic $\mathrm{Ca}^{2+}$ due to RYR1 $\mathrm{Ca}^{2+}$ leak ${ }^{24,25,79}$, we found that activation of brown fat thermogenic activity enhances the heat sensitivity of the YS mice. Under normal housing conditions, the YS mice display a small but significant increase in body temperature compared to their WT littermates. Body temperature before the $37^{\circ} \mathrm{C}$ heat exposure correlates with the severity of the response of the mice to the $37^{\circ} \mathrm{C}$ heat exposure. Factors that increase body temperature by activating adaptive thermogenesis, such as housing in the cold, food intake, and $\beta_{3} \mathrm{AR}$ agonizts increase the probability that the YS mice will die in the heat exposure. In contrast, reducing UCP1 levels or blocking $\beta_{3} \mathrm{AR}$ receptors increases the probability that the mice will survive the heat exposure. These data suggest that adaptive thermogenesis from either cold exposure or $\beta_{3} \mathrm{AR}$ stimulation increases the sensitivity of the YS mice to heat and UCP1 expression is required for this sensitization.

While adaptive thermogenesis is essential for maintaining body temperature in all mammals, our data with the YS mice suggest that adaptive thermogenesis may be detrimental to MHS individuals with significant heat-sensitivity. Specifically, activation of adaptive thermogenesis can overcompensate when an individual with an RYR1 mutation who has adapted to inside air conditioning goes outside into the heat. In this type of situation, adaptive thermogenesis could become maladaptive by further sensitizing these individuals with $R Y R 1$ mutations to a heat response. Maintaining thermoneutral conditions and allowing adequate time to adjust to the hot outdoor temperatures before engaging in exercise or sports could decrease the risk of heat response in these individuals. In addition, individuals with these heat-sensitive $R Y R 1$ mutations should take extra precautions to manage other sources of core temperature elevation, such as exercise, stress, infection, and thermogenic drugs.

An unexpected finding of our study was that the male YS mice have more BAT compared to their WT littermates, raising the question of the mechanism underlying the increased BAT. A number of browning factors have been previously identified ${ }^{95,96}$. While we found no increase in norepinephrine, we did detect a small, but significant, increase in epinephrine that could contribute to increased activation of $\mathrm{BAT}^{97}$. We also detected a large increase in circulating lactate in YS mice in the absence of heat exposure. Both lactate and epinephrine elevate UCP1 levels in adipose tissue ${ }^{75,76,98}$. To determine if the altered activity of the mutated RYR1 in skeletal muscle was responsible for the increase in circulating lactate, we measured glycogen levels in the muscle of YS and WT mice. We found substantial decreases in muscle glycogen in the muscle of the YS mice, suggesting that glycogen breakdown followed by glycolysis in muscle is the source of the circulating lactate. Our data suggest that glycogen breakdown and increased circulating lactate are being driven by increased muscle energy demands driven by increased cytosolic $\mathrm{Ca}^{2+}$. We did not find decreases in glycogen or glucose in the liver, suggesting that the liver is functioning normally.

Lactate plays diverse roles as a metabolic substrate and a signaling molecule ${ }^{99}$ but can also promote tumor growth by serving as an energy source ${ }^{100,101}$. Using primary cells from the stromovascular fraction of BAT from mice and a hTERT cell line, we found that lactate promotes brown adipogenesis by increasing the proliferation and differentiation of preadipocytes, but not by transdifferentiation of mature adipocytes. While the optimal approach to defining the effects of lactate on BAT would be in vivo studies, lactate should be tested during perinatal or even prenatal development when the stem cell population is the most abundant. Moreover, chronic pharmacological MCT inhibition in vivo in adult mice caused severe adverse effects systemically, likely due to the blocking of essential lactate-dependent metabolic processes ${ }^{102,103}$. The short window of opportunity during early development render feasible interventions in post-weaning pups difficult. Nevertheless, our study lays the foundations for future research to explore the effects of lactate on BAT. Development of novel genetic models, such as Mct1 $1^{\text {loxp }}$ mice could be used to target lactate influx in a tissue specific manner ${ }^{104}$. Maternal delivery of lactate across placenta ${ }^{105}$ during pregnancy could potentially be used to test the effect of lactate in tissues during early development. Finally, 3D cultures of engineered organoids developed from adipose tissue SVF could serve as an intermediate system between in vitro and in vivo studies ${ }^{106}$.

While brown fat thermogenic activity is not the underlying cause of the heat-sensitivity, our findings suggest it is a sensitizing component of the feed-forward cycle of heat-induced hypermetabolic response in YS mice. Additional studies are needed to elucidate the mechanism by which lactate increases BAT in mice and to determine if lactate plays a similar role in individuals with $R Y R 1$ variants associated with heat sensitivity.

In summary, while adaptive thermogenesis is essential for maintaining body temperature in all mammals, our results suggest that it can be detrimental to individuals with $R Y R 1$ variants associated with MHS and heat-sensitivity. Specifically, activation of adaptive thermogenesis in response to the cold overcompensates upon transition to a warmer temperature. This overcompensation can render adaptive thermogenesis maladaptive. The common practices for setting indoor air-conditioning systems are largely geared toward human comfort and tend to overcompensate for elevated outdoor temperatures. For individuals with MHS and heat sensitivity this type of cold to hot temperature transition poses an acute risk. Simple and relatively minor lifestyle modifications such as slightly raising indoor temperatures $\left(>21^{\circ} \mathrm{C}, 70^{\circ} \mathrm{F}\right)$ at home and not going outside in the summer immediately after eating could reduce the risk of a lifethreatening response of children and young adult males with RYR1 mutations to heat. Since body temperature plays a critical role in the response to heat, this vulnerable population should also be concerned about other factors that increase body temperature such as exercise in warm, humid environments, febrile illness, drugs that elevate body temperature and/or combinations of these factors ${ }^{13}$.

\section{Methods}

Human subjects. The institutional research ethics board (REB) at the University of Toronto approved this retrospective clinical study and waived the need for informed consent due to the retrospective nature of the study. Patients referred to the MH investigation unit (MHIU) at Toronto General Hospital between 1994 and 2019, who had significant heat sensitivity or heat-induced rhabdomyolysis AND carried a variant in $R Y R 1$ were included. The significant heat sensitivity was defined as per patient's report as suffering from heat exhaustion, occurrence of heat stroke or heat-induced rhabdomyolysis. Collected data included RYR1 variants, gender, age at the time of assessment of heat sensitivity, description of symptoms, information on $\mathrm{MH}$ reaction if existed (clinical grading scale score), caffeine and halothane contracture results were available, blood lactate levels where available, and previous anesthetic history. The same information from family members, who carried the same genetic variant was collected. Clinical case reports published between 1980 and 2019 were systematically reviewed as previously described ${ }^{38}$ to identify additional eligible patients, using the preferred reporting items for systematic reviews and meta-analysis guidelines. The statement and checklists for the systematic reviews and meta-analysis are provided as Supplementary Notes 1-3. 
The institutional REB approval and consent wavier are provided as Supplementary Note 4 . This waiver covers both consent to participate and consent to publish.

Mice. The institutional animal care and use committee (IACUC) at Baylor College of Medicine approved all protocols for animal experiments in this study. All studies with mice were preformed according to ethical standards for research using animals. Mice are housed in 14-h light, 10-h dark cycle in a temperature-controlled environment (Supplementary Fig. 4) with $40-60 \%$ humidity in a pathogen barrier level 3 facility. The heating, ventilation, and air-conditioning (HVAC) systems of the housing facility are regulated and monitored by the building automation system (BAS). Indoor temperature, humidity, and animal health status were also monitored daily by animal care staff at the center for comparative medicine (CCM). Mice are given access to food and water ad libitum and provided with a nestlets enriched cage environment. PicoLab ${ }^{\circledR}$ Select rodent diet 5V5R (LabDiet) is provided as the mouse normal chow diet, and chlorine dioxide treated water is provided as drinking water. Single housing conditions, noises, vibrations, and excessive handlings are kept at a minimum to reduce stress. Mice are weaned at 3 weeks of age and are tested at the specified age for each experiment. The mice with a heat-

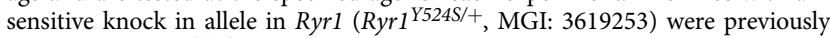
created by our lab ${ }^{24,79}$, and maintained on C57BL/6J genetic background. The mice with a cold-sensitive knockout allele in $U_{c p 1}\left(\mathrm{Ucp}^{-1-}\right.$, MGI: 1857471) were obtained from the Jackson Laboratory (JAX 003124 ), kindly gifted to our lab by Dr. Ashley Chen from the Department of Pediatrics at Baylor College of Medicine and maintained on C57BL/6J genetic background. All in vivo data were retrieved from at least three independent experimental animal cohorts.

Metabolic measurements. Energy balance parameters, including locomotor movement, ambulatory activity, feeding, drinking, and calorimetry, were simultaneously assessed by the comprehensive lab animal monitoring systems (CLAMS, Columbus Instruments). Twenty-four hour urine monitoring and collection, and additional monitoring for accumulative food and water intake were assessed in metabolic cages (TECNIPLAST). Lean body mass was assessed with dual-energy Xray absorptiometry (DEXA, Lunar PIXImus). Baseline body temperatures were assessed with IPTT-300 temperature transponder (BioMedic Data Systems) for repeated measurements, and with RightTemp rectal thermometer (PhysioSuite ${ }^{\star}$, Kent Scientific) for one-time measurements. Temperature acclimation to cold $\left(4{ }^{\circ} \mathrm{C}\right)$ or warm $\left(30^{\circ} \mathrm{C}\right)$ condition was regulated by the environment-controlled enclosures (CLAMS-ENC70, Columbus Instruments). For experiments requiring temperature conditioning, mice were conditioned at the specified temperatures for 1 week prior to assessment for thermogenic capacity. To determine the effects of temperature conditioning on adaptive thermogenesis, core body temperatures were measured between 1 and $2 \mathrm{~h}$ after return to room temperature following the conditioning at either 4 or $30^{\circ} \mathrm{C}$. All temperature measurements were performed during the same time each day in the afternoon $(2: 00-4: 00 \mathrm{pm})$ to reduce influences from circadian regulations.

Heat response. To assess the heat response of mice, we exposed mice to an elevated environmental temperature at $37^{\circ} \mathrm{C}$ (unless specifically indicated) for 15 $\mathrm{min}$ in a temperature-controlled enclosure (IITC Life Science). The heat exposure temperature was digitally regulated and additionally confirmed by a scientific mercury thermometer. Experimental mice (drug treated or Ucp1-ablated) and littermate control mice (vehicle-treated or Ucp1-WT) were exposed to heat in pairs simultaneously. To assess the heat sensitivity of mice over a temperature range, mice within a controlled age range were randomized into separate cohorts, and each cohort was exposed to a specified temperature. Oxygen consumption, carbon dioxide production, respiratory exchange ratio, and heat production were monitored and recorded during each heat exposure by Oxymax system for indirect calorimetry (IDC, Columbus Instruments). Core body temperature was assessed with RightTemp ${ }^{\star}$ rectal thermometer (PhysioSuite ${ }^{\circledR}$, Kent Scientific) before and after heat exposure to determine the extent of heat-induced hyperthermic response. For heat exposure experiment following physiological modulation of adaptive thermogenesis, mice were exposed to heat approximately $1-2 \mathrm{~h}$ after 1-week temperature conditioning at the specified temperature. To evaluate the effects of pharmacological modulation of $\beta_{3}$ adrenergic receptors $\left(\beta_{3} \mathrm{AR}\right), \beta_{3} \mathrm{AR}$ agonist, antagonist, or vehicles were injected to mice intraperitoneally $10 \mathrm{~min}$ prior to heat exposure. The agonist (BRL37344 and CL316243) and antagonist (L748337) for $\beta_{3} \mathrm{AR}$ were reconstituted as stock solutions based on manufactures recommendations (TOCRIS) and diluted in saline to reach dosage of $1 \mathrm{mg} / \mathrm{kg}$ per mouse. Signs of stress and survival of mice were continuously monitored during heat exposure, hourly within $6 \mathrm{~h}$, and every $6 \mathrm{~h}$ within $48 \mathrm{~h}$ after heat exposure by the experimenter. Mice were additionally monitored daily for health status by CCM. All heat exposure experiments were performed during the same time each day in the afternoon $(2: 00-4: 00 \mathrm{pm})$ to reduce influences from circadian regulations.

PET/CT imaging. The detection of brown fat activity in mice using a small animal dedicated PET and CT (micro-PET/CT) system with ${ }^{18} \mathrm{~F}-\mathrm{FDG}$ (Cyclotope) has been previously described ${ }^{107}$. Specifically, mice were fasted overnight and exposed to cold temperature in $4^{\circ} \mathrm{C}$ environment for $4 \mathrm{~h}$ before receiving $300 \mu \mathrm{Ci}$ of ${ }^{18} \mathrm{~F}$ FDG via intraperitoneal (i.p.) injection. The mice remained in the cold conditions for an additional hour after FDG injection, for a total of $5 \mathrm{~h}$ prior to the imaging. CT scans $(5 \mathrm{~min})$ immediately followed by PET scans $(30 \mathrm{~min})$ were acquired for mice under anesthesia with isoflurane $(2 \%$ in oxygen at $1.5 \mathrm{~L} / \mathrm{min})$ with the Inveon integrated PET/CT system (Siemens). Mutant mice and WT littermate control mice were imaged in pairs simultaneously. The quantification of brown fat volume and activity based on PET/CT functional imaging has been previously described ${ }^{108}$. Specifically, the acquired PET scans were reconstructed using OSEM3D reconstruction method and registered to the CT scan for attenuation correction and anatomical references. Major BAT was identified near the interscapular region, and adipose depots were confirmed with low-density regions in CT images of -300 to 100 in Hounsfield units. BAT was defined as having a metabolic activity above a threshold of standard uptake value (SUV) for ${ }^{18} \mathrm{~F}$-FDG $\left(\mathrm{SUV}_{\mathrm{LBM}} \geq 3 \mathrm{~g} / \mathrm{mL}\right)$. Total BAT activity was calculated as the product of brown fat volume and mean uptake activity $\left(\mathrm{BAT}_{\text {activity }}=\mathrm{BAT}_{\text {volume }} \times \mathrm{SUV}_{\text {mean }}\right)$. The pharmacokinetic coefficient for each animal is calculated as the slope of the linear regression for brown fat ${ }^{18} \mathrm{~F}$ FDG SUV ${ }_{\max }$ over time during the 30 min of imaging. Mice that had an $\mathrm{MH}$ response and died during imaging were not included in the analysis.

NMR spectroscopy. Hindlimb muscles from mice were scanned on a Bruker $9.4 \mathrm{~T}$ magnetic resonance imaging system to measure in vivo $\mathrm{PCr}, \mathrm{Pi}$, and adenosine triphosphate (ATP levels). The ${ }^{31} \mathrm{P}$ NMR spectra were collected using an Image Selected in vivo spectroscopy sequence with a $T R=2 \mathrm{~s}, \mathrm{NA}=192$. Free induction decay was zero filled and a line broadening of $20 \mathrm{~Hz}$ was applied before the Fourier transformation. Analysis for ${ }^{31} \mathrm{P}$ NMR spectra were done using Topspin within the Paravision 5.1 software. The $\alpha$ and $\beta$ ATP peaks were used for the ATP assessments. Intracellular $\mathrm{pH}$ was determined using the equation:

$$
\mathrm{pH}=6.75+\log \left[\frac{(\mathrm{CS}-3.27)}{(5.69-\mathrm{CS})}\right]
$$

where CS is the chemical shift between PCr and Pi.

Muscle basal tension. Soleus muscle isolation and basal tension assessment were performed as described previously ${ }^{24,25}$. Briefly, intact soleus muscles were isolated from mice, mounted to a force transducer, and placed in a chamber containing oxygenated Krebs-Ringer buffer. A series of electrical stimulations for single twitches (train rate: $1 \mathrm{tps}$, train duration: $200 \mathrm{~ms} /$ train, stimulation duration: $0.2 \mathrm{~ms} /$ pulse, voltage: $20 \mathrm{~V}$, resistance: $25 \Omega$ ) was applied to muscle at varying mounting length to adjust mounting to the its optimal length. Optimal length is defined as the length of muscle at which it generates the strongest isometric tension in response to twitch stimulation. To test the temperature-dependent increase in basal tension, temperature of the buffer was warmed from room temperature to $37.0^{\circ} \mathrm{C}$. Isometric basal tension was monitored by the force transducer for $15 \mathrm{~min}$ at $37.0^{\circ} \mathrm{C}$ without electrical stimulations to identify maximum tension during the measurement period. Following the basal tension measurement, muscle length and muscle weight were measured to estimate physiological cross-sectional area (CSA) of the muscle, as:

$$
\mathrm{CSA}=\frac{m}{l_{o}} \times \rho,
$$

where $m$ is the measured muscle mass $(g), l_{o}$ is the measured muscle optimal length $(\mathrm{cm})$, and $\rho$ is the mammalian muscle density constant $\left.\left(1.06 \mathrm{~g} / \mathrm{cm}^{3}\right)^{109}\right]$. Basal tension was calculated and expressed as specific stress based on maximum tension and CSA of the muscle, as:

$$
S=\frac{F}{\mathrm{CSA}}
$$

where $S$ is the specific stress $\left(\mathrm{N} / \mathrm{cm}^{2}\right), F$ is the measured maximal tension $(N)$, and CSA is the calculated muscle physiological CSA $\left(\mathrm{cm}^{2}\right)$

Histology. Adipose tissues were paraffin-embedded, sectioned, and stained with Hematoxylin-Eosine (H\&E) staining by the pathology and histology core at BCM. For immunofluorescent staining of mitochondrial uncoupling protein (UCP1), paraffin sections of inguinal fat from littermate mice were rehydrated, blocked in PBST (0.1 M phosphate buffer, pH 7.4 with $0.5 \mathrm{M} \mathrm{NaCl}$ and $0.5 \%$ Triton X-100) with $5 \%$ bovine serum albumin (PBSTB), and treated anti-UCP1 antibody (Abcam) at a dilution factor of 1:400 in the PBSTB. After washing twice with PBST for 10 min each, sections were treated with Alexa-Fluor 488 (Invitrogen) at a dilution factor of 1:200 at RT for 90 min followed by washing with PBST. At the final washing, DAPI (Invitrogen, $0.3 \mu \mathrm{M}$ ) was used for nuclei staining. Imaging was performed with the fluorescent microscope (Olympus IX81). Interscapular BAT from mice were embedded in OCT compound (Tissue-Tek ${ }^{\circ}$ ), frozen in 2methylbutane precooled in liquid nitrogen, and frozen-sectioned with SHANDON cryostat microtome (Thermo Electron Corporation). These sections were blocked in the PBSTB, treated with anti-CD36 (NOVUS Biologicals) and anti-FATP1 (Santa Cruz, 1:400) The remaining steps are the same as above except for the fluorescent secondary Ab combinations: Alex Fluor 488 for FATP1 and Alexa Fluor 594 (Invitrogen) for CD36. Secondary antibodies were diluted at a dilution factor of 1:200 in PBS. The remaining procedures are the same with histology of paraffin sections. Microscopy was performed with image acquisition software for fluorescent microscopy (IX81, Olympus) and bright-field microscopy (NIS, Nikon). 
Preparation of primary SVF cells. Adipose tissue from interscapular or inguinal region were excised from mice for brown or white SVF, minced, and digested with $0.2 \%$ collagen type II (Worthington Biochemical) in SVF primary cells isolation buffer (100 mM HEPES, pH 7.4, $123 \mathrm{mM} \mathrm{NaCl}, 5 \mathrm{mM} \mathrm{KCl}, 1.3 \mathrm{mM} \mathrm{CaCl}, 5 \mathrm{mM}$ glucose, $1 \times$ penicillin/streptomycin, and $4 \%$ fraction $\mathrm{V}$ bovine serum albumin (Sigma)) for $30 \mathrm{~min}$ in shaking incubator set at $37^{\circ} \mathrm{C} / 150 \mathrm{rpm}$. During enzyme digestion in the shaking incubator, tubes were vortexed for 10 seconds every $5 \mathrm{~min}$. After enzyme digestion, tubes with enzyme-digested solution were put on ice for $30 \mathrm{~min}$ to allow the mature adipocytes and lipid droplets to float. Clear part of enzyme-digested solution filtered through $70 \mu \mathrm{m}$ cell strainer (BD Bioscience) and centrifuged at $700 \times g$ for 10 min to pulldown SVF primary cells. After washing cell pellet with DMEM, SVF primary cell pellet was resuspended with prewarmed growth medium (DMEM with high glucose, $20 \%$ fetal bovine serum (FBS), and antibiotics) and plated on the cell culture dishes.

Cell culture. The mouse preadipocyte cell line (3T3L1) and human immortalized BAT SVF cells (hTERTA41hBAT-SVF) (ATCC ${ }^{\oplus}$ ) were cultured and maintained in the growth medium, high glucose DMEM (Gibco) with 10\% FBS (ATCC ${ }^{\circ}$ for 3T3L1 and GenDEPOT (Opti-Gold) for human BAT SVF) and antibiotics (Gibco). For differentiation assays, cells were differentiated to induce UCP1 as described previously ${ }^{110}$. Confluent cells were treated with induction medium (differentiation medium (DMEM with $10 \%$ FBS) supplemented with dexamethasone (Sigma, $2 \mu \mathrm{g} / \mathrm{ml}$ ), IBMX (Sigma, $0.5 \mathrm{mM}$ ), insulin (Sigma, $5 \mu \mathrm{g} / \mathrm{ml}$ ), Rosiglitazone (Sigma, $1 \mu \mathrm{g} / \mathrm{ml}$ ), and $\mathrm{T}_{3}$ (Sigma, $50 \mathrm{nM}$ ) for 2 days followed by changing into differentiation medium (DMEM with $10 \%$ FBS, IBMX, insulin, Rosiglitazone, and $\mathrm{T}_{3}$ up to indicated time period. Differentiating cells were treated with sodium-L-lactate (Sigma-Aldrich) at the indicated concentration, mouse serum of YS and WT littermates (10\% instead of FBS), deproteinized plasma of YS and WT littermates (20\% instead of FBS) and/or ARC155858 (MedChemExpress, $0.1 \mu \mathrm{M}$ ) in the differentiation medium for 24-48 h. Cells were then lysed in RIPA buffer and loaded on $12 \%$ sodium dodecyl sulfate polyacrylamide gel electrophoresis (SDS-PAGE) gel for the Western blotting against UCP1 as an adipocyte marker. For proliferation assays, proliferating SVF cells were maintained in the growth medium and harvested prior to complete confluence, without adipogenic induction.

Flow cytometry. Flow cytometry analysis of cells in primary SVF and cultured SVF cells in the iBAT and has been previously described 78,111 . For primary SVF cells, adipose tissue from interscapular region was excised from neonates at P2.5, minced in phosphate-buffered saline (PBS), digested with collagenase, and filtered through $70 \mu \mathrm{m}$ cell strainer. For cultured SVF cells, adherent cells in dish were harvested by gentle scrapping without use of trypsin. Collected cells were immediately resuspended in standard flow cytometry (FC) staining buffer (containing $0.1 \%$ sodium azide, Sigma). Directly conjugated antibodies (anti-PDGFRa/CD140a-PE, 1:400, eBioscience) was added to cell pallet to stain surface antigens in dark at $4{ }^{\circ} \mathrm{C}$ for $45 \mathrm{~min}$. After washing the cell pallets with FC staining buffer, $100 \mu \mathrm{l}$ of $4 \%$ paraformaldehyde was added to fix the cells for $15 \mathrm{~min}$, and cells were subsequently permeabilized with $100 \mu \mathrm{l}$ 0.2\% Triton X-100 (Sigma). After additional washing with FC staining buffer, directly conjugated antibodies (anti-EBF2-AlexaFluor647, $1: 50$, Bioss) and DAPI ( $1 \mu \mathrm{g} / \mathrm{mL}$, BioLegend) was added to cell pallet to stain nuclear targets in dark at $4{ }^{\circ} \mathrm{C}$ for $45 \mathrm{~min}$. After final washing, FC data for stained cells were acquired on the flow cytometer (LSRFortessa, BD) using FC acquisition software (FACSDiva, BD) within $24 \mathrm{~h}$. Cell populations were screened for single cells by FSC, side scatter and DAPI gating, and analyzed for frequencies and fluorescent intensities (FlowJo, BD). Cell cycle analysis was performed based on the quantitative DAPI intensity for DNA content by the default univariate cell cycle model without constrains. A figure exemplifying gating strategy is provided in the Supplementary Fig. 15.

Immunoblot analysis. Snap-frozen mouse tissues were homogenized with tissue homogenizer (Precellys) at $4{ }^{\circ} \mathrm{C}$ in a radioimmunoprecipitation assay (RIPA) buffer $(150 \mathrm{mM} \mathrm{NaCl}, 1 \% \mathrm{NP}-40,0.5 \%$ sodium deoxycholate, $0.1 \% \mathrm{SDS}$, and $50 \mathrm{mM}$ Tris $\mathrm{pH}$ 8.0) with freshly added protease inhibitor and phosphatase inhibitor cocktails (GenDEPOT). Adipose tissue samples were kept at $4{ }^{\circ} \mathrm{C}$ for additional $1 \mathrm{~h}$, centrifuged at $4{ }^{\circ} \mathrm{C}$ for $20 \mathrm{~min}$ at $12,000 \times \mathrm{g}$, and the aqueous lysates were collected to determine protein concentration with Pierce BCA protein assay (Thermo Scientific). Samples were diluted with $5 \times$ SDS sample buffer to $1 \times(2 \%$ SDS, $1 \% 2$ mercaptoethanol, $10 \%$ glycerol, $0.004 \%$ bromophenol blue, and $50 \mathrm{mM}$ Tris- $\mathrm{HCl}$ ) and denatured at $95^{\circ} \mathrm{C}$ for $5 \mathrm{~min}$. Two to ten microgram of iBAT, $30 \mu \mathrm{g}$ of iWAT, and $60 \mu \mathrm{g}$ of muscle and cell lysates were resolved by SDS-PAGE, transferred to PVDF and blotted with specific primary antibodies at dilutions specified by manufacturer: anti-UCP1 (Abcam, AB10983, 1:1000) and anti-Tubulin (DSHB, 6G7, 1:500), anti-CYC (Cell Signaling, 1:1000), anti-PGC1a (Santa Cruz, 1:500). Fluorescent secondary antibodies were used to visualize protein bands on the Odyssey CLx Imager (LI-COR) and/or ChemiDoc ${ }^{\mathrm{MP}}$ Imaging System (Bio-Rad), and protein band intensities were quantified by Image J. All antibodies used are listed in Supplementary Table 1.

Gene expression analysis. Total RNA was extracted from mouse tissues using TRIzol reagent (Life Technologies). Total RNA $(1 \mu \mathrm{g})$ was reverse transcribed into
cDNA using the iScript cDNA Synthesis Kit (BIO-RAD). Gene expression assay was performed with the iQ SYBR Green Supermix (BIO-RAD) on ViiA 7 RealTime PCR System (Applied Biosystems). Samples were run in technical triplicates, and specificity of the amplified products was confirmed by melting curve analysis The slope of standard curves is used to estimate the PCR amplification efficiency. Relative gene expression of target genes was determined based on the reaction cycle threshold values calibrated for PCR efficiency using the Pfaffl method as ${ }^{112}$

$$
\text { Relative expression ratio }=\frac{\left(E_{\text {target }}\right)^{\Delta \mathrm{CT} \text { target }}(\text { control-sample })}{\left(E_{\text {reference }}\right)^{\Delta \mathrm{CT} \text { reference }} \text { (control-sample) }},
$$

where $E_{\text {target }}$ is the amplification efficiency of the target gene $(S \ln )$, Ereference is the amplification efficiency of the reference gene $(R n 18 s)$, and $\Delta \mathrm{CT}$ is the cycle threshold deviation of the control (WT)-sample (mutant) for each gene. The following primer sets were used:

$\sin 5^{\prime}$-GCACTAGGTCCTTGGCATGT- $3^{\prime}$ (forward);

$\sin 5^{\prime}$-ACTCAAGGGACTGGCAGAGA-3' (reverse);

Ucp 1 5'-AGGCTTCCAGTACCATTAGGT-3' (forward);

Ucp1 5'-CTGAGTGAGGCAAAGCTGATTT-3' (reverse);

Ppargcla 5'-TATGGAGTGACATAGAGTGTGCT-3' (forward);

Ppargcla 5'-CCACTTCAATCCACCCAGAAAG-3' (reverse);

Cidea $5^{\prime}$-TGACATTCATGGGATTGCAGAC-3' (forward);

Cidea $5^{\prime}$-GGCCAGTTGTGATGACTAAGAC-3' (reverse);

Rn18s 5'-GTAACCCGTTGAACCCCATT-3' (forward);

Rn18s 5'-CCATCCAATCGGTAGTAGCG-3' (reverse).

\section{Circulating factors. The MILLIPLEX ${ }^{\circledast}$ (MMYOMAG-74K, EMD Millipore)} mouse myokine assay was used to assess the serum level of a panel of myokines quantitatively, including brain-derived neurotrophic factor, interleukin 6 (IL6), interleukin 15 (IL15), fibroblast growth factor 21 (FGF21), fractalkine, follistatinlike protein 1 (FSTL1), myostatin (MSTN), irisin, leukemia inhibitory factor, oncostatin M, osteocrin, osteonectin. MILLIPLEX assay was performed with data acquisition platform (Luminex, EMD Millipore). Proteome Profiler ${ }^{\mathrm{TM}}$ antibody arrays were used to assess the relative level of an additional panel of 111 soluble proteins in mouse serum (ARY028, R\&D Systems). In addition, enzyme-linked immunosorbent assays were used to quantitatively determine the serum levels of IL6 (M60000B, R\&D Systems) and total urinary excretion of epinephrine and norepinephrine (KA1877, Abnova). Clinical chemistries for thyroid hormone $\left(\mathrm{T}_{4}\right)$ and other diagnostic mouse blood factors were assessed by the comparative pathology laboratory at BCM.

Blood lactate assay. Blood was collected from the mice by retro-orbital bleeding using heparinized capillary tubes under anesthesia and centrifuged at $2000 \times g$ at $4^{\circ} \mathrm{C}$ for $10 \mathrm{~min}$. The clear phase of plasma was filtered through a $10 \mathrm{kDa}$ cut-off column and then measured for lactate by the commercial kit (BioVision) according to the manufacturer's instruction. Briefly, the deproteinized plasma was diluted in the assay buffer in 1 to 100 on a 96-well plate, followed by adding reaction mixture. The plate was incubated at room temperature for $30 \mathrm{~min}$ in the dark. The optical density was measured in a microplate reader (BioTek) at $570 \mathrm{~nm}$ wavelength.

Tissue glycogen and glucose assays. Gastrocnemius and liver were analyzed for glycogen and glucose levels using a commercial kit (BioVision). The assay was performed according to the manufacturer's protocol. Briefly, each muscle was homogenized in $500 \mu \mathrm{l}$ of deionized water with a bead beater (Bertin instruments). The homogenates were boiled for $10 \mathrm{~min}$ and centrifuged at $18,000 \times g$ for $10 \mathrm{~min}$ at $4{ }^{\circ} \mathrm{C}$. The clear supernatant was diluted in the hydrolysis buffer in $1-5$ on a $96-$ well plate and incubated with hydrolysis enzyme mixture at room temperature for $30 \mathrm{~min}$ in the dark. The optical density at $570 \mathrm{~nm}$ wavelength was measured in a microplate reader (BioTek). The glycogen and glucose levels were normalized to the protein concentrations.

RPPA. RPPA of skeletal muscle tissues were performed at the Functional Proteomics RPPA Core Facility the University of Texas MD Anderson Cancer Center The following full description of RPPA protocol can be found at the core facility (https://www.mdanderson.org/research/research-resources/core-facilities/ functional-proteomics-rppa-core/education-and-references.html): "Cellular proteins were denatured by $1 \%$ SDS (with Beta-mercaptoethanol) and diluted in five 2 -fold serial dilutions in dilution lysis buffer. Serial diluted lysates were arrayed on nitrocellulose-coated slides (Grace Bio Lab) by Aushon 2470 Arrayer (Aushon BioSystems). Total 5808 array spots were arranged on each slide including the spots corresponding to serial diluted: (1) Standard Lysates; (2) positive and negative controls prepared from mixed cell lysates or dilution buffer, respectively. Each slide was probed with a validated primary antibody plus a biotin-conjugated secondary antibody. Only antibodies with a Pearson correlation coefficient between RPPA and western blotting of greater than 0.7 were used for RPPA. Antibodies with a single or dominant band on western blotting were further assessed by direct comparison to RPPA using cell lines with differential protein expression or modulated with ligands/inhibitors or siRNA for phospho- or structural proteins, respectively. The signal obtained was amplified using a Dako 
Cytomation-Catalyzed system (Dako) and visualized by DAB colorimetric reaction. The slides were scanned, analyzed, and quantified using a customized-software to generate spot intensity. Each dilution curve was fitted with a logistic model ("Supercurve Fitting" developed by the Department of Bioinformatics and Computational Biology in MD Anderson Cancer Center, "http://bioinformatics. mdanderson.org/OOMPA"). This fits a single curve using all the samples (i.e., dilution series) on a slide with the signal intensity as the response variable and the dilution steps are independent variable. The fitted curve is plotted with the signal intensities both observed and fitted on the $y$-axis and the $\log 2$-concentration of proteins on the $x$-axis for diagnostic purposes. The protein concentrations of each set of slides were then normalized for protein loading. Correction factor was calculated by: (1) median centering across samples of all antibody experiments; and (2) median centering across antibodies for each sample."

Mass spectrometry. Peptides from the filtered serum samples were analyzed at the Mass Spectrometry Proteomics Core at BCM. Serum filtered through an Amicon $10 \mathrm{~K}$ centrifugal filter device $(20 \mu \mathrm{l})$ was digested by trypsin (20:1 trypsin to peptide ratio) overnight at $37{ }^{\circ} \mathrm{C}$. The digestion was stopped with $0.1 \%$ formic acid. Samples $(4 \mu \mathrm{l})$ were analyzed using a nano-HPLC 1200 (Thermo Scientific) coupled to an Orbitrap Fusion ${ }^{\mathrm{TM}}$ Lumos $^{\mathrm{TM}}$ Tribrid $^{\mathrm{TM}}$ (Fusion, Thermo Scientific) mass spectrometer. Samples were enriched using a $2 \mathrm{~cm} \times 100 \mu \mathrm{m}$ i.d. trap column with $1.9 \mu \mathrm{m}$ Reprosil-Pur Basic C18 beads (Dr. Maisch HPLC GmbH, Germany) and separated with an $5 \mathrm{~cm} \times 150 \mu \mathrm{m}$ capillary column packed with $1.9 \mu \mathrm{m}$ Reprosil-Pur Basic C18 beads. A 45-min discontinuous gradient of 2-24\% acetonitrile and $0.1 \%$ formic acid at a flow rate of $800 \mathrm{nl} / \mathrm{min}$ was applied to column then electro-sprayed into the mass spectrometer. The MS1 spectrum was acquired in the Orbitrap with a resolution of 120,000 and $m / z$ range of 300-1400. HCD fragmented MS2 spectra were acquired in ion-trap with rapid scan mode operated under the control of Xcalibur (software ver 4.1.50, Thermo Fisher Scientific) in data-dependent mode, acquiring fragmentation spectra of the top 30 ions. The MS/ MS spectra were searched against target-decoy NCBI mouse RefSeq database (release January 2019, containing 48,156 entries) in Proteome Discoverer 2.1 interface (Thermo Fisher) with Mascot algorithm (Mascot 2.4, Matrix Science). Dynamic alterations in acetylation of the N-terminal amino acid and oxidation of methionines were allowed. The precursor mass tolerance was confined within $20 \mathrm{ppm}$ with fragment mass tolerance of 0.5 Dalton and a maximum of two missed cleavages was allowed. Assigned peptides were filtered with $1 \%$ false-discovery rate using Percolator validation based on $q$-value. Shared peptides were split proportionally to corresponding unique peptide ratios. Peptides were grouped into gene products and shared peptides are split proportionally to corresponding unique peptide ratios as previously described ${ }^{113}$. Briefly, peptides were mapped to gene products (collapsing all protein isoforms that originate from the same genetic locus). Gene products are quantified by $\mathrm{BBAQ}^{114}$, with modification. For peptides that map to more than one gene product, peptide peak area is distributed in a weighted procedure based on unique peptide ratios. For each peptide shared across multiple gene products, the peptide peak area assigned to gene product is defined as:

$$
s_{A}=\frac{\sum u_{A}}{\sum u_{A}+\sum u_{B}+\ldots},
$$

where $u_{i, A}$ is one of each unique-to-gene peptide for gene product $A$, and $(A, B \ldots$,$) are$ all gene products to which shared peptide $s$ maps. For cases where no unique-to-gene peptides exist, shared peptide quantities are divided evenly across all gene products. Shared peptides were split proportionally to corresponding unique peptide ratios.

Resting calcium in FDB fibers. Flexor digitorum brevis fibers (FDB) fibers were loaded with $5 \mu \mathrm{M}$ Fura-2 AM (Thermo Scientific, Waltham, MA) for $30 \mathrm{~min}$ at room temperature in control Ringer's solution ( $146 \mathrm{mM} \mathrm{NaCl}, 5 \mathrm{mM} \mathrm{KCl}, 2 \mathrm{mM}$ $\mathrm{CaCl} 2,1 \mathrm{mM} \mathrm{MgCl} 2,10 \mathrm{mM}$ HEPES, $\mathrm{pH}$ 7.4). Fibers were then treated for $30 \mathrm{~min}$ with dye-free Ringer's solution supplemented with either $10 \mu \mathrm{M}$ agonist (CL316243) or $10 \mu \mathrm{M}$ antagonist (SR $59230 \mathrm{~A}$ ). Fibers were then placed in a temperature-controlled chamber (Dagan, Corp., Minneapolis, MN) on the stage of an inverted epifluorescence microscope (Nikon Inc., Melville, NY) and alternatively excited at 340 and $380 \mathrm{~nm}$ (30 ms exposure per wavelength and $2 \times 2$ binning) using a Polychrome V monochromator-based illumination system (TILL Photonics, Munich, Germany). Fluorescence images were captured (510 nm emission) using a high speed, digital SENSICAM-QE CCD camera (Cooke, Romulus, MI). Ratio images $(R=\mathrm{F} 340 / \mathrm{F} 380)$ were generated using TILL Vision software (TILL Photonics, Pleasanton, CA) and mean resting values calculated using Image (NIH) for data recorded at both 25 and $37^{\circ} \mathrm{C}$. For each condition, resting ratio images were first collected from several fibers in the dish while the temperature was held at $25^{\circ} \mathrm{C}$. The temperature of the bath was then equilibrated to $37^{\circ} \mathrm{C}$ for $10-15 \mathrm{~min}$ and then the same fibers were re-imaged at the higher temperature. Fura-2 fluorescence ratios $(R=\mathrm{F} 340 / \mathrm{F} 380)$ were converted to free $\mathrm{Ca}^{2+}$ concentrations using an in situ calibration approach described previously ${ }^{79}$ and the following equation ${ }^{115}$

$$
\left[\mathrm{Ca}^{2+}\right] \mathrm{i}=K_{\mathrm{d}} \times \beta \times\left(\left(R-R_{\min }\right) /\left(R_{\max }-R\right)\right),
$$

where $K_{\mathrm{d}}$ is the $\mathrm{Ca}^{2+}$ affinity of Fura-2, $\beta$ is the ratio of the $380-\mathrm{nm}$ emission recorded under $\mathrm{Ca}^{2+}$-free and $\mathrm{Ca}^{2+}$ saturating conditions, $R_{\min }$ is the emission ratio under $\mathrm{Ca}^{2+}$-free conditions, and $R_{\max }$ is the emission ratio under $\mathrm{Ca}^{2+}$ saturating conditions. The values of $\beta, R_{\min }$, and $R_{\max }$ were determined experimentally. The $K_{\mathrm{d}}$ used was taken from the in vitro calibration of Fura- 2 in the presence of $27 \mathrm{mg} \mathrm{ml}^{-1}$ of aldolase $\left(428 \mathrm{nM}^{116}\right)$ and was assumed to be independent of the temperature in intact cells as shown previously ${ }^{117}$.

Bioinformatics. The pathogenicity scores of the $R Y R 1$ variants in patients with heat sensitivity are predicted with polymorphism phenotyping (PolyPhen) bioinformatics as described previously ${ }^{43}$. Mutant amino acid residues were aligned onto the linear residue spans of RYR1 subdomains as designated previously ${ }^{44}$, and visualized on the three-dimensional structure of the rabbit RYR1 homolog based on data from protein data bank (PDB ID: 5T15) with the Chimera program

Statistical analysis. Appropriate statistical analyses were applied as specified in the figure legends using Prism 8 (GraphPad Software). Sample sizes were determined based on power analysis of preliminary results or estimated based on similar previous studies when preliminary results were not available. All experiments were assessed in distinct samples, and the sample sizes $(n)$ indicate the number of biological replicates. No samples were excluded from the statistical analysis unless specifically stated otherwise. Values were presented as mean \pm standard deviation $P<0.05$ was required to be considered as statistically significant. All statistical tests are two-sided.

The following figures contain analysis of multiple parameters measured from the same experiments: Heat response: $\operatorname{maxVO}_{2}, \operatorname{maxVCO}{ }_{2}$, core body temperature, and survival rate analysis (Figs. 1-4, SF.2); CLAMS study: $\mathrm{VO}_{2}$, $\mathrm{VCO}_{2}$, RER, heat, and activities (SF.3). Baseline core body temperature: core body temperature distribution and littermate pair analysis (Figs. 2 and 3); PET/CT imaging: brown fat volume, brown fat activity, and brown fat total volume analysis (Fig. 5, SF.7); Adipose tissue browning: UCP1, PGC1a, and other mitochondrial markers in immunoblot analysis (Fig. 5, SF.8); NMR imaging: $\mathrm{PCr}$, Pi, and ATP analysis (Fig. 6, SF.9). High-throughput arrays: analysis for circulating factors from the cytokine array panel, myokine array panel, and clinical chemistry panel, analysis for muscle proteomics RPPA panels (Fig. 6, SF.10 and SF.12); High-throughput FC: cell cycle analysis for cell frequencies in G1, S, and G2 phases (Fig. 7, SF.11). Analysis of heat response for age dependence (Fig. 1), ambient/body temperature dependence (Figs. 2 and 3), and analysis of heat sensitivity (Fig. 4) are based on measurements from distinct animal subjects at the indicated conditions, and the same subjects were NOT heat-exposed and measured repeatedly.

Reporting summary. Further information on research design is available in the Nature Research Reporting Summary linked to this article.

\section{Data availability}

All data generated or analyzed during this study are included in this published article and its supplementary files. Source data are provided with this paper. The mass spectrometry data have been deposited via the Mass Spectrometry Interactive Virtual Environment (MassIVE) repository. Source data are provided with this paper and open for the public: MSV000085803.

Diagnostic MH mutations are obtained from European Malignant Hyperthermia Group (www.emhg.org) and are publicly available. Structures of RYR1 are generated based on data from protein data bank (PDB ID: 5T15) and are publicly available. Source data are provided with this paper.

\section{Code availability}

This paper does not report custom code. Source data are provided with this paper.

Received: 25 February 2020; Accepted: 18 September 2020; Published online: 09 October 2020

\section{References}

1. Monnier, N., Procaccio, V., Stieglitz, P. \& Lunardi, J. Malignant-hyperthermia susceptibility is associated with a mutation of the alpha 1-subunit of the human dihydropyridine-sensitive L-type voltage-dependent calcium-channel receptor in skeletal muscle. Am. J. Hum. Genet. 60, 1316-1325 (1997).

2. Wappler, F. Anesthesia for patients with a history of malignant hyperthermia. Curr. Opin. Anaesthesiol. 23, 417-422 (2010).

3. Monnier, N. et al. Presence of two different genetic traits in malignant hyperthermia families: implication for genetic analysis, diagnosis, and incidence of malignant hyperthermia susceptibility. Anesthesiology 97, 1067-1074 (2002)

4. Brady, J. E., Sun, L. S., Rosenberg, H. \& Li, G. Prevalence of malignant hyperthermia due to anesthesia in New York State, 2001-2005. Anesth. Analg. 109, 1162-1166 (2009). 
5. Strazis, K. P. \& Fox, A. W. Malignant hyperthermia: a review of published cases. Anesth. Analg. 77, 297-304 (1993).

6. Larach, M. G., Gronert, G. A., Allen, G. C., Brandom, B. W. \& Lehman, E. B. Clinical presentation, treatment, and complications of malignant hyperthermia in North America from 1987 to 2006. Anesth. Analg. 110, 498-507 (2010).

7. Ibarra Moreno, C. A. et al. An assessment of penetrance and clinical expression of malignant hyperthermia in individuals carrying diagnostic ryanodine receptor 1 gene mutations. Anesthesiology 131, 983-991 (2019).

8. Rosenberg, H., Pollock, N., Schiemann, A., Bulger, T. \& Stowell, K. Malignant hyperthermia: a review. Orphanet J. Rare Dis. 10, 93 (2015).

9. Lopez, R. J. et al. An RYR1 mutation associated with malignant hyperthermia is also associated with bleeding abnormalities. Sci. Signal 9, ra68 (2016).

10. Tobin, J. R., Jason, D. R., Challa, V. R., Nelson, T. E. \& Sambuughin, N. Malignant hyperthermia and apparent heat stroke. J. Am. Med. Assoc. 286, 168-169 (2001).

11. Wappler, F. et al. Evidence for susceptibility to malignant hyperthermia in patients with exercise-induced rhabdomyolysis. Anesthesiology 94, 95-100 (2001).

12. Davis, M. et al. Malignant hyperthermia associated with exercise-induced rhabdomyolysis or congenital abnormalities and a novel RYR1 mutation in New Zealand and Australian pedigrees. Br. J. Anaesth. 88, 508-515 (2002).

13. Groom, L. et al. Identical de novo mutation in the type 1 ryanodine receptor gene associated with fatal, stress-induced malignant hyperthermia in two unrelated families. Anesthesiology 115, 938-945 (2011).

14. Potts, L. E. et al. Improving awareness of nonanesthesia-related malignant hyperthermia presentations: a tale of two brothers. A Case Rep. 3, 23-26 (2014).

15. Muldoon, S., Deuster, P., Voelkel, M., Capacchione, J. \& Bunger, R. Exertional heat illness, exertional rhabdomyolysis, and malignant hyperthermia: is there a link? Curr. Sports Med. Rep. 7, 74-80 (2008).

16. Sambuughin, N. et al. The ryanodine receptor type 1 gene variants in African American men with exertional rhabdomyolysis and malignant hyperthermia susceptibility. Clin. Genet. 76, 564-568 (2009).

17. Lavezzi, W. A. et al. Case report: death in the emergency department: an unrecognized awake malignant hyperthermia-like reaction in a six-year-old. Anesth. Analg. 116, 420-423 (2013).

18. Capacchione, J. F. et al. Exertional rhabdomyolysis and malignant hyperthermia in a patient with ryanodine receptor type 1 gene, L-type calcium channel alpha-1 subunit gene, and calsequestrin-1 gene polymorphisms. Anesthesiology 112, 239-244 (2010).

19. Dlamini, N. et al. Mutations in RYR1 are a common cause of exertional myalgia and rhabdomyolysis. Neuromuscul. Disord. 23, 540-548 (2013).

20. Matthews, E. et al. Atypical periodic paralysis and myalgia: a novel RYR1 phenotype. Neurology 90, e412-e418 (2018).

21. Snoeck, M. et al. "Human Stress Syndrome" and the expanding spectrum of RYR1-related myopathies. Cell Biochem. Biophys. 74, 85-87 (2016).

22. Molenaar, J. P. et al. Fever-induced recurrent rhabdomyolysis due to a novel mutation in the ryanodine receptor type 1 gene. Intern. Med. J. 44, 819-820 (2014).

23. Hosokawa, Y. et al. Round table on malignant hyperthermia in physically active populations: meeting proceedings. J. Athl. Train. 52, 377-383 (2017).

24. Chelu, M. G. et al. Heat- and anesthesia-induced malignant hyperthermia in an RyR1 knock-in mouse. FASEB J. 20, 329-330 (2006).

25. Durham, W. J. et al. RyR1 S-nitrosylation underlies environmental heat stroke and sudden death in Y522S RyR1 knockin mice. Cell 133, 53-65 (2008).

26. Michelucci, A. et al. Strenuous exercise triggers a life-threatening response in mice susceptible to malignant hyperthermia. FASEB J. 31, 3649-3662 (2017).

27. Bal, N. C. et al. Both brown adipose tissue and skeletal muscle thermogenesis processes are activated during mild to severe cold adaptation in mice. J. Biol. Chem. 292, 16616-16625 (2017)

28. Pant, M., Bal, N. C. \& Periasamy, M. Sarcolipin: a key thermogenic and metabolic regulator in skeletal muscle. Trends Endocrinol. Metab. 27, 881-892 (2016).

29. Periasamy, M., Herrera, J. L. \& Reis, F. C. G. Skeletal muscle thermogenesis and its role in whole body energy metabolism. Diabetes Metab. J. 41, 327-336 (2017).

30. Periasamy, M. et al. Role of SERCA pump in muscle thermogenesis and metabolism. Compr. Physiol. 7, 879-890 (2017).

31. Fedorenko, A., Lishko, P. V. \& Kirichok, Y. Mechanism of fatty-aciddependent UCP1 uncoupling in brown fat mitochondria. Cell 151, 400-413 (2012).

32. Kissig, M., Shapira, S. N. \& Seale, P. SnapShot: brown and beige adipose thermogenesis. Cell 166, 258-258 e251 (2016).

33. Fenzl, A. \& Kiefer, F. W. Brown adipose tissue and thermogenesis. Horm. Mol. Biol. Clin. Investig. 19, 25-37 (2014).

34. Smith, R. E. \& Horwitz, B. A. Brown fat and thermogenesis. Physiol. Rev. 49, 330-425 (1969).
35. Cypess, A. M. et al. Identification and importance of brown adipose tissue in adult humans. N. Engl. J. Med. 360, 1509-1517 (2009).

36. van Marken Lichtenbelt, W. D. et al. Cold-activated brown adipose tissue in healthy men. N. Engl. J. Med. 360, 1500-1508 (2009).

37. Virtanen, K. A. et al. Functional brown adipose tissue in healthy adults. $N$. Engl. J. Med. 360, 1518-1525 (2009).

38. Kraeva, N., Sapa, A., Dowling, J. J. \& Riazi, S. Malignant hyperthermia susceptibility in patients with exertional rhabdomyolysis: a retrospective cohort study and updated systematic review. Can. J. Anaesth. 64, 736-743 (2017).

39. Riazi, S., Kraeva, N. \& Hopkins, P. M. Malignant hyperthermia in the postgenomics era: new perspectives on an old concept. Anesthesiology 128, 168-180 (2018).

40. Capacchione, J. F. \& Muldoon, S. M. The relationship between exertional heat illness, exertional rhabdomyolysis, and malignant hyperthermia. Anesth. Analg. 109, 1065-1069 (2009).

41. Butala, B. \& Brandom, B. Muscular body build and male sex are independently associated with malignant hyperthermia susceptibility. Can. J. Anaesth. 64, 396-401 (2017).

42. Rosenberg, H., Davis, M., James, D., Pollock, N. \& Stowell, K. Malignant hyperthermia. Orphanet J. Rare Dis. 2, 21 (2007).

43. Adzhubei, I. A. et al. A method and server for predicting damaging missense mutations. Nat. Methods 7, 248-249 (2010).

44. des Georges, A. et al. Structural basis for gating and activation of RyR1. Cell 167, 145-157 el17 (2016).

45. Yang, T. et al. Pharmacologic and functional characterization of malignant hyperthermia in the R163C RyR1 knock-in mouse. Anesthesiology 105, 1164-1175 (2006).

46. Yuen, B. et al. Mice expressing T4826I-RYR1 are viable but exhibit sex- and genotype-dependent susceptibility to malignant hyperthermia and muscle damage. FASEB J. 26, 1311-1322 (2012)

47. Lopez, J. R., Kaura, V., Diggle, C. P., Hopkins, P. M. \& Allen, P. D. Malignant hyperthermia, environmental heat stress, and intracellular calcium dysregulation in a mouse model expressing the p.G2435R variant of RYR1. Br. J. Anaesth. 121, 953-961 (2018).

48. Tseng, Y. H., Cypess, A. M. \& Kahn, C. R. Cellular bioenergetics as a target for obesity therapy. Nat. Rev. Drug Discov. 9, 465-482 (2010).

49. Ganeshan, K. \& Chawla, A. Warming the mouse to model human diseases. Nat. Rev. Endocrinol. 13, 458-465 (2017).

50. Mueez, U. D. et al. Postprandial oxidative metabolism of human brown fat indicates thermogenesis. Cell Metab. 28, 207-216 e203 (2018).

51. De Matteis, R., Ricquier, D. \& Cinti, S. TH-, NPY-, SP-, and CGRPimmunoreactive nerves in interscapular brown adipose tissue of adult rats acclimated at different temperatures: an immunohistochemical study. J. Neurocytol. 27, 877-886 (1998).

52. Krief, $\mathrm{S}$. et al. Tissue distribution of beta 3-adrenergic receptor mRNA in man. J. Clin. Investig. 91, 344-349 (1993).

53. Hiraoka, Y. et al. Critical roles of nardilysin in the maintenance of body temperature homoeostasis. Nat. Commun. 5, 3224 (2014).

54. Rowland, L. A., Bal, N. C., Kozak, L. P. \& Periasamy, M. Uncoupling protein 1 and sarcolipin are required to maintain optimal thermogenesis, and loss of both systems compromises survival of mice under cold stress. J. Biol. Chem. 290, 12282-12289 (2015).

55. Rowland, L. A., Maurya, S. K., Bal, N. C., Kozak, L. \& Periasamy, M. Sarcolipin and uncoupling protein 1 play distinct roles in diet-induced thermogenesis and do not compensate for one another. Obesity 24, 1430-1433 (2016).

56. Andronache, Z., Hamilton, S. L., Dirksen, R. T. \& Melzer, W. A retrograde signal from RyR1 alters DHP receptor inactivation and limits window $\mathrm{Ca}^{2+}$ release in muscle fibers of Y522S RyR1 knock-in mice. Proc. Natl Acad. Sci. USA 106, 4531-4536 (2009)

57. Manno, C. et al. Altered $\mathrm{Ca}^{2+}$ concentration, permeability and buffering in the myofibre $\mathrm{Ca}^{2+}$ store of a mouse model of malignant hyperthermia. J. Physiol. 591, 4439-4457 (2013).

58. Wu, J., Cohen, P. \& Spiegelman, B. M. Adaptive thermogenesis in adipocytes: is beige the new brown? Genes Dev. 27, 234-250 (2013).

59. Bartelt, A. \& Heeren, J. Adipose tissue browning and metabolic health. Nat. Rev. Endocrinol. 10, 24-36 (2014).

60. Hargreaves, M. Skeletal muscle metabolism during exercise in humans. Clin Exp. Pharm. Physiol. 27, 225-228 (2000).

61. Cohen, P. et al. Identification of the $\mathrm{Ca}^{2+}$-dependent modulator protein as the fourth subunit of rabbit skeletal muscle phosphorylase kinase. FEBS Lett. 92, 287-293 (1978).

62. Herzig, S. \& Shaw, R. J. AMPK: guardian of metabolism and mitochondrial homeostasis. Nat. Rev. Mol. Cell Biol. 19, 121-135 (2018).

63. Ortenblad, N., Westerblad, H. \& Nielsen, J. Muscle glycogen stores and fatigue. J. Physiol. 591, 4405-4413 (2013).

64. Hawley, S. A. et al. Characterization of the AMP-activated protein kinase kinase from rat liver and identification of threonine 172 as the major site at 
which it phosphorylates AMP-activated protein kinase. J. Biol. Chem. 271, 27879-27887 (1996).

65. Yang, J. et al. Store-operated calcium entry-activated autophagy protects EPC proliferation via the CAMKK2-MTOR pathway in ox-LDL exposure. Autophagy 13, 82-98 (2017).

66. Woods, A. et al. $\mathrm{Ca}^{2+} /$ calmodulin-dependent protein kinase kinase-beta acts upstream of AMP-activated protein kinase in mammalian cells. Cell Metab. 2, 21-33 (2005).

67. Hurley, R. L. et al. The $\mathrm{Ca}^{2+} /$ calmodulin-dependent protein kinase kinases are AMP-activated protein kinase kinases. J. Biol. Chem. 280, 29060-29066 (2005).

68. Steinberg, G. R. \& Carling, D. AMP-activated protein kinase: the current landscape for drug development. Nat. Rev. Drug Discov. 18, 527-551 (2019).

69. Jorgensen, S. B., Richter, E. A. \& Wojtaszewski, J. F. Role of AMPK in skeletal muscle metabolic regulation and adaptation in relation to exercise. J. Physiol. 574, 17-31 (2006).

70. Bargut, T. C., Aguila, M. B. \& Mandarim-de-Lacerda, C. A. Brown adipose tissue: updates in cellular and molecular biology. Tissue Cell 48, 452-460 (2016).

71. Mazzeo, R. S. \& Marshall, P. Influence of plasma catecholamines on the lactate threshold during graded exercise. J. Appl. Physiol. (1985) 67, 1319-1322 (1989).

72. Stainsby, W. N., Sumners, C. \& Andrew, G. M. Plasma catecholamines and their effect on blood lactate and muscle lactate output. J. Appl. Physiol. Respir. Environ. Exerc. Physiol. 57, 321-325 (1984).

73. Stainsby, W. N., Sumners, C. \& Eitzman, P. D. Effects of catecholamines on lactic acid output during progressive working contractions. J. Appl. Physiol. (1985) 59, 1809-1814 (1985).

74. Andersson, D. C. et al. Stress-induced increase in skeletal muscle force requires protein kinase A phosphorylation of the ryanodine receptor. $J$. Physiol. 590, 6381-6387 (2012).

75. Carriere, A. et al. Browning of white adipose cells by intermediate metabolites: an adaptive mechanism to alleviate redox pressure. Diabetes 63, 3253-3265 (2014).

76. Petersen, C. et al. MCT1 and MCT4 expression and lactate flux activity increase during white and brown adipogenesis and impact adipocyte metabolism. Sci. Rep. 7, 13101 (2017).

77. $\mathrm{Xu}, \mathrm{X}$. et al. Exercise ameliorates high-fat diet-induced metabolic and vascular dysfunction, and increases adipocyte progenitor cell population in brown adipose tissue. Am. J. Physiol. Regul. Integr. Comp. Physiol. 300, R1115-1125 (2011).

78. Wang, W. et al. Ebf2 is a selective marker of brown and beige adipogenic precursor cells. Proc. Natl Acad. Sci. USA 111, 14466-14471 (2014).

79. Lanner, J. T. et al. AICAR prevents heat-induced sudden death in RyR1 mutant mice independent of AMPK activation. Nat. Med. 18, 244-251 (2012).

80. Aaboud, M. et al. Combination of searches for invisible Higgs Boson decays with the ATLAS experiment. Phys. Rev. Lett. 122, 231801 (2019).

81. Brandom, B. W. \& Muldoon, S. M. Unexpected MH deaths without exposure to inhalation anesthetics in pediatric patients. Paediatr. Anaesth. 23, 851-854 (2013).

82. Kochling, A., Wappler, F., Winkler, G. \& Schulte am Esch, J. S. Rhabdomyolysis following severe physical exercise in a patient with predisposition to malignant hyperthermia. Anaesth. Intensive Care 26, 315-318 (1998).

83. Ryan, J. F. \& Tedeschi, L. G. Sudden unexplained death in a patient with a family history of malignant hyperthermia. J. Clin. Anesth. 9, 66-68 (1997).

84. Carsana, A. Exercise-induced rhabdomyolysis and stress-induced malignant hyperthermia events, association with malignant hyperthermia susceptibility, and RYR1 gene sequence variations. Sci. World J. 2013, 531465 (2013).

85. Hall, A. P. \& Henry, J. A. Acute toxic effects of 'Ecstasy' (MDMA) and related compounds: overview of pathophysiology and clinical management. Br. J. Anaesth. 96, 678-685 (2006).

86. Knoblauch, M., Dagnino-Acosta, A. \& Hamilton, S. L. Mice with RyR1 mutation (Y524S) undergo hypermetabolic response to simvastatin. Skelet. Muscle 3, 22 (2013).

87. Metterlein, T. et al. Statins alter intracellular calcium homeostasis in malignant hyperthermia susceptible individuals. Cardiovasc. Ther. $\mathbf{2 8}$ 356-360 (2010).

88. Walter, E. J., Hanna-Jumma, S., Carraretto, M. \& Forni, L. The pathophysiological basis and consequences of fever. Crit. Care 20, 200 (2016).

89. Lu, Z., Rosenberg, H. \& Li, G. Prevalence of malignant hyperthermia diagnosis in hospital discharge records in California, Florida, New York, and Wisconsin. J. Clin. Anesth. 39, 10-14 (2017)

90. Betz, M. J. \& Enerback, S. Targeting thermogenesis in brown fat and muscle to treat obesity and metabolic disease. Nat. Rev. Endocrinol. 14, 77-87 (2018).

91. Fuller-Jackson, J. P. \& Henry, B. A. Adipose and skeletal muscle thermogenesis: studies from large animals. J. Endocrinol. 237, R99-R115 (2018).
92. Celi, F. S., Le, T. N. \& Ni, B. Physiology and relevance of human adaptive thermogenesis response. Trends Endocrinol. Metab. 26, 238-247 (2015).

93. Gilsanz, V., Hu, H. H. \& Kajimura, S. Relevance of brown adipose tissue in infancy and adolescence. Pediatr. Res. 73, 3-9 (2013).

94. Hu, H. H. et al. Comparison of brown and white adipose tissues in infants and children with chemical-shift-encoded water-fat MRI. J. Magn. Reson Imaging 38, 885-896 (2013).

95. Stanford, K.I. \& Goodyear, L.J. Muscle-adipose tissue cross talk. Cold Spring Harb. Perspect. Med. 8, a209801 (2018)

96. Collins, S. \& Surwit, R. S. The beta-adrenergic receptors and the control of adipose tissue metabolism and thermogenesis. Recent Prog. Horm. Res. 56, 309-328 (2001)

97. Cypess, A. M. et al. Activation of human brown adipose tissue by a beta3adrenergic receptor agonist. Cell Metab. 21, 33-38 (2015).

98. Sharara-Chami, R. I., Joachim, M., Mulcahey, M., Ebert, S. \& Majzoub, J. A. Effect of epinephrine deficiency on cold tolerance and on brown adipose tissue. Mol. Cell Endocrinol. 328, 34-39 (2010).

99. Hashimoto, T. \& Brooks, G. A. Mitochondrial lactate oxidation complex and an adaptive role for lactate production. Med. Sci. Sports Exerc. 40, 486-494 (2008).

100. Sonveaux, P. et al. Targeting lactate-fueled respiration selectively kills hypoxic tumor cells in mice. J. Clin. Investig. 118, 3930-3942 (2008)

101. Hensley, C. T. et al. Metabolic heterogeneity in human lung tumors. Cell 164, 681-694 (2016).

102. Fisel, P., Schaeffeler, E. \& Schwab, M. Clinical and functional relevance of the monocarboxylate transporter family in disease pathophysiology and drug therapy. Clin. Transl. Sci. 11, 352-364 (2018).

103. Perez-Escuredo, J. et al. Monocarboxylate transporters in the brain and in cancer. Biochim. Biophys. Acta 1863, 2481-2497 (2016).

104. Jha, M. K. et al. Monocarboxylate transporter 1 in Schwann cells contributes to maintenance of sensory nerve myelination during aging. Glia 68, 161-177 (2020).

105. Illsley, N. P., Wootton, R., Penfold, P., Hall, S. \& Duffy, S. Lactate transfer across the perfused human placenta. Placenta 7, 209-220 (1986).

106. Daquinag, A. C., Souza, G. R. \& Kolonin, M. G. Adipose tissue engineering in three-dimensional levitation tissue culture system based on magnetic nanoparticles. Tissue Eng. Part C Methods 19, 336-344 (2013).

107. Wang, X., Minze, L. J. \& Shi, Z. Z. Functional imaging of brown fat in mice with 18F-FDG micro-PET/CT. J. Vis. Exp. e4060 (2012).

108. Leitner, B. P. et al. Mapping of human brown adipose tissue in lean and obese young men. Proc. Natl Acad. Sci. USA 114, 8649-8654 (2017)

109. Segal, S. S., White, T. P. \& Faulkner, J. A. Architecture, composition, and contractile properties of rat soleus muscle grafts. Am. J. Physiol. 250, C474-479 (1986).

110. Asano, H. et al. Induction of beige-like adipocytes in 3T3-L1 cells. J. Vet. Med. Sci. 76, 57-64 (2014).

111. Kilroy, G., Dietrich, M., Wu, X., Gimble, J. M. \& Floyd, Z. E. Isolation of murine adipose-derived stromal/stem cells for adipogenic differentiation or flow cytometry-based analysis. Methods Mol. Biol. 1773, 137-146 (2018)

112. Pfaffl, M. W. A new mathematical model for relative quantification in realtime RT-PCR. Nucleic Acids Res. 29, e45 (2001).

113. Saltzman, A. B. et al. gpGrouper: a peptide grouping algorithm for genecentric inference and quantitation of bottom-up proteomics data. Mol. Cell Proteom. 17, 2270-2283 (2018).

114. Schwanhausser, B. et al. Global quantification of mammalian gene expression control. Nature 473, 337-342 (2011).

115. Grynkiewicz, G., Poenie, M. \& Tsien, R. Y. A new generation of $\mathrm{Ca}^{2+}$ indicators with greatly improved fluorescence properties. J. Biol. Chem. 260, 3440-3450 (1985).

116. Konishi, M., Olson, A., Hollingworth, S. \& Baylor, S. M. Myoplasmic binding of fura-2 investigated by steady-state fluorescence and absorbance measurements. Biophys. J. 54, 1089-1104 (1988).

117. Uto, A., Arai, H. \& Ogawa, Y. Reassessment of Fura-2 and the ratio method for determination of intracellular $\mathrm{Ca}^{2+}$ concentrations. Cell Calcium 12, 29-37 (1991).

\section{Acknowledgements}

This study was supported by the multi-PI national institute of health (NIH) grant (R01AR053349) to S.L.H., R.C.D., and S.Y.J., and a merit award from Department of Anesthesia, University of Toronto, Canada to SR. H.J.W. was supported in part by the American Heart Association (AHA) predoctoral fellowship award (17PRE33411184) to H.J.W. and the Howard Hughes Medical Institutes (HHMI) Med into Grad Initiative awarded to the Translational Biology and Molecular Medicine (TBMM) Graduate Program. L.B. was supported by NIH Training Grant T32HL007676. A.D.H. is supported by NIH AR072602 and by an MDA Development Grant (548809). T.C. is also supported by NIH R01072602. The BCM proteomics core is supported by P30CA125123 and CPRIT RP170005. We also acknowledge the invaluable resources provided by the Baylor College of Medicine (BCM) cytometry and cell sorting core (CCSC), integrated microscopy core 
(IMC), mouse metabolic phenotyping core (MMPC), pathology and histology core (PHC), mass spectrometry proteomics core (MSPC), comparative pathology laboratory (CPL), and the small animal imaging facility (SAIF) at Texas Children's Hospital. The RPPA were performed at the MD Anderson RPPA core facility. The data on daily indoor temperature of the animal housing facility were monitored and kindly provided by animal care staff at the BCM center for CCM. The trend data from BAS on HVAC systems of the animal housing facility were kindly provided by BCM facility services.

\section{Author contributions}

All authors were involved in project design discussed and analyzed the data as it was generated, and contributed to the paper preparation. All have read, critiqued and approved the final draft of the paper. H.J.W. and C.S.L. designed most of the adaptive thermogenesis experiments, analyzed data, created the figures, and helped write the paper. The following individuals designed and analyzed the experiments indicated. R.S.Z.Y.: CLAMS studies and data from the female mice. L.G.: effects of $\beta 3 A R$ agonist and antagonists on intracellular $\mathrm{Ca}^{2+}$ handling in FDB fibers. I.F.: data on human subjects, including demographics, clinical characteristics, genetics and contracture results. L.B.: effects of $\beta 3 \mathrm{AR}$ agonist and antagonists on basal tension. D.K.G.: effects of cold temperatures on the YS mice and effects of age on the heat response. J.H.: lactate and glycogen data. A.D.H.: effects of $4 \mathrm{~h}$ cold exposure data on the YS mice and eliminated a role for RYR1 in adipogenesis. J.R.: effect of food intake on the heat response. J.M.C.: mass spec data. T.C.: SLN levels in UCP1 KO mice. N.H.A.: resting metabolic rate in the YS mice. J.R.: NMR data to obtain ATP, PCr, Pi levels in muscle. PS:18F-PET/CT. N.V.: provided unidentified human case data and insight into the clinical condition. M.W.G.: 18F-PET/CT experiments. S.Y.J.: mass spec analysis and interpretation of proteomic data. M.L.B.: mapped the positions of the heat-sensitive mutations in the 3D structure of RYR1. R.G.P.: supervised the NMR experiments, R.T.D.: provided and analyzed the $\mathrm{Ca}^{2+}$ data and was involved in all stages of the study. S.R.: involved in all aspects of the study design, provided the unidentified data on patients with MHS and heat sensitivity and measured lactate levels in patient sera. S.L.H.: the senior investigator for the study, and involved in all aspects of study design, including data analysis and preparation of the paper.

\section{Competing interests}

The authors declare no competing interests.

\section{Additional information}

Supplementary information is available for this paper at https://doi.org/10.1038/s41467020-18865-z.

Correspondence and requests for materials should be addressed to S.L.H.

Peer review information Nature Communications thanks the anonymous reviewer(s) for their contribution to the peer review of this work.

Reprints and permission information is available at http://www.nature.com/reprints

Publisher's note Springer Nature remains neutral with regard to jurisdictional claims in published maps and institutional affiliations.

(c) Open Access This article is licensed under a Creative Commons Attribution 4.0 International License, which permits use, sharing, adaptation, distribution and reproduction in any medium or format, as long as you give appropriate credit to the original author(s) and the source, provide a link to the Creative Commons license, and indicate if changes were made. The images or other third party material in this article are included in the article's Creative Commons license, unless indicated otherwise in a credit line to the material. If material is not included in the article's Creative Commons license and your intended use is not permitted by statutory regulation or exceeds the permitted use, you will need to obtain permission directly from the copyright holder. To view a copy of this license, visit http://creativecommons.org/ licenses/by/4.0/.

(C) The Author(s) 2020 